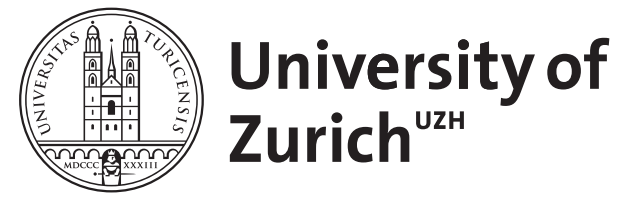

\title{
Seeds of Distrust: Conflict in Uganda
}

\author{
Rohner, Dominic ; Thoenig, Mathias ; Zilibotti, Fabrizio
}

\begin{abstract}
We study the effect of civil conflict on social capital, focusing on the experience of Ugandaduring the last decade. Using individual and county-level data, we document large causal effects on trust and ethnic identity of an exogenous outburst of ethnic conflicts in 2002-05. We exploit two waves of survey data from Afrobarometer 2000 and 2008, including information on socioeconomic characteristics at the individual level, and geo-referenced measures of fi ghting events from ACLED.Our identifi cation strategy exploits variations in the intensity of fighting both in the spatial and cross-ethnic dimensions. We fi nd that more intense fighting decreases generalized trust and increases ethnic identity. The effects are quantitatively large and robust to a number of control variables, alternative measures of violence, and different statistical techniques involving ethnic and spatial fi xed effects and instrumental variables. Controlling for the intensity of violence during the conflict, we also document that post-conflict economic recovery is slower in ethnically fractionalized counties.Our findings are consistent with the existence of a self-reinforcing process between conflicts and ethnic cleavages.
\end{abstract}

DOI: https://doi.org/10.1007/s10887-013-9093-1

Posted at the Zurich Open Repository and Archive, University of Zurich

ZORA URL: https://doi.org/10.5167/uzh-74295

Conference or Workshop Item

Originally published at:

Rohner, Dominic; Thoenig, Mathias; Zilibotti, Fabrizio (2012). Seeds of Distrust: Conflict in Uganda. In: 3rd Development Economics Workshop, University of Tilburg, 21 June 2012 - 22 June 2012.

DOI: https://doi.org/10.1007/s10887-013-9093-1 


\title{
Seeds of Distrust: Conflict in Uganda*
}

\author{
Dominic Rohner; Mathias Thoenig $\ddagger$ Fabrizio Zilibotti ${ }^{\S}$ \\ This version: April 2012 // First version: April 2011
}

\begin{abstract}
We study the effect of civil conflict on social capital, focusing on the experience of Uganda during the last decade. Using individual and county-level data, we document large causal effects on trust and ethnic identity of an exogenous outburst of ethnic conflicts in 2002-05. We exploit two waves of survey data from Afrobarometer 2000 and 2008, including information on socioeconomic characteristics at the individual level, and geo-referenced measures of fighting events from ACLED. Our identification strategy exploits variations in the intensity of fighting both in the spatial and cross-ethnic dimensions. We find that more intense fighting decreases generalized trust and increases ethnic identity. The effects are quantitatively large and robust to a number of control variables, alternative measures of violence, and different statistical techniques involving ethnic and spatial fixed effects and instrumental variables. Controlling for the intensity of violence during the conflict, we also document that post-conflict economic recovery is slower in ethnically fractionalized counties. Our findings are consistent with the existence of a self-reinforcing process between conflicts and ethnic cleavages.
\end{abstract}

${ }^{*}$ The title of the first version (April 2011) was "Seeds of Distrust? Conflict in Uganda". We thank David Schönholzer and Nathan Zorzi for excellent research assistance, and are grateful for comments to Erwin Bulte, Stefano Della Vigna, Oeindrilla Dube, Ernst Fehr, Pauline Grosjean, Andreas Itten, Hannes Müller, Nathan Nunn, Florian Pelgrin, Torsten Persson, David Strömberg, Jakob Svensson, Marie-Anne Valfort, Leonard Wantchekon, and conference and seminar participants at the University of Neuchâtel (6.5.2011), "Concentration on Conflict" meeting in Barcelona (21.5.2011), Annual Meeting of the Society of Economic Dynamics in Ghent (8.7.2011), University of Gothenburg (7.9.2011), IIES-Stockholm University (8.9.2011), "First Meeting on Institutions and Political Economy" in Lisbon (8.9.2011), Workshop on the "Political Economy of Governance and Conflicts" in Namur (26.11.2011), Keio University (20.1.2012) and University of Paris 1 Panthéon-Sorbonne (16.2.2012). We also thank Henrik Pilgaard from UNHCR for sharing with us data on internally displaced people in Uganda. Dominic Rohner acknowledges financial support from the Swiss National Science Foundation (grant no. 100014-122636). Fabrizio Zilibotti acknowledges financial support from the ERC Advanced Grant IPCDP-229883.

${ }^{\dagger}$ Department of Economics, University of Zurich. Email: dominic.rohner@econ.uzh.ch.

${ }^{\ddagger}$ Department of Economics, University of Lausanne. Email: mathias.thoenig@unil.ch.

${ }^{\S}$ Department of Economics, University of Zurich. Email: fabrizio.zilibotti@econ.uzh.ch. 


\section{Introduction}

This paper investigates from an empirical perspective the effect of civil conflict on social capital, focusing on the experience of Uganda during the last decade. Civil conflicts have persistent devastating effects on economic development (DeRouen and Bercovitch 2008, Collier and Hoeffler 2004, Collier, Hoeffler and Rohner 2009, Quinn, Mason and Gurses 2007, and Walter 2004). Their legacy involves more than physical and human capital destruction. The aftermaths of civil conflicts are often plagued by the breakdown of civic and economic cooperation within society. We are motivated by recent theoretical work (Rohner, Thoenig and Zilibotti 2011; Acemoglu and Wolitzky 2012), arguing that war leads to a collapse of trust and social capital which in turn carries the seeds of further ethnic conflicts. Yet, there are instances in which wars appear to cement rather than destroy cooperation. Historically, wars promoted nation building in Europe (Tilly 1975), while the aftermath of World War II in Western Europe was characterized by strong institutional development involving social cooperation, renewed national identity and sustained high economic growth (Eichengreen 2008). While the post-war dynamics of international conflicts are arguably different from those of civil wars, Bellows and Miguel (2009) also report evidence of positive social capital developments in Sierra Leone after the devastating civil conflict of 1991-2002. ${ }^{1}$ The goal of this paper is to address two questions: First, is there evidence of causal effects of war on inter-ethnic trust? Second, how do such effects differ across different dimensions of trust and social capital?

We document causal effects of ethnic conflict on trust and ethnic identity using individual, countyand district-level data from Uganda. Uganda is a natural environment for such a micro-study. It is an ethnic mosaic consisting of at least 52 groups. Ethnic (or ethnic-related) conflicts have been pervasive in this country at least since independence in 1962. The history of military coups and violent regime changes is associated with the hegemony of different ethnic groups, the main divide being that between the Nilotic people of the North, and the Bantu people of the South. Since 1985, Uganda has been ruled by the National Resistance Movement (NRM) led by Yoweri Museveni, who participated first in the demise of Idi Amin Dada, and then in the rebellion against Amin's successor (and former predecessor), Milton Obote. Although generally viewed as non sectarian, Museveni's government has its main constituency in the Bantu-dominated South, while it has faced resilient opposition and armed rebellion in the North of the country, especially in the "Acholiland" region. The Acholi people, traditionally the warrior elite of Uganda, had been loyal to Obote and have remained by-and-large alienated from the NMR. The main military challenge against the government has come from the Lord's Resistance Army (LRA), a sectarian Acholi-nationalistic group led by Joseph Kony and active in Northern Uganda. Not only Acholiland has been troubled by rebellion. The second most important rebel army, the Allied Democratic Forces (ADF), running on an Islamic radical agenda, was active in the Western border area of Uganda, close to the border with the Democratic Republic of Congo.

\footnotetext{
${ }^{1}$ Bellows and Miguel (2009) use a household survey to analyze whether people who have been victimized in the civil war in Sierra Leone are affected in their post-war behavior. In particular, they find that more victimized people are more likely to "attend community meetings", and to "join social and political groups".
} 
Other areas have also been troubled by traditional tribal and ethnic conflicts.

Our empirical strategy exploits an exogenous change in the policy against internal insurgency that occurred in 2001, after the September 11 attack. The declaration of "war against terror" was a turning point. In earlier years, the international community had tried without much success to promote negotiated settlements of the Ugandan conflicts. ${ }^{2}$ In 2001, the US Patriot Act officially declared the LRA and the ADF to be terrorist organizations. Among its consequences, the ruling Sudanese National Islamic Front that had secured sanctuary and military hardware to the LRA withdrew its support to the rebel army. These shifts provided the opportunity for Museveni's government to pursue a military crackdown on the rebel armies. ${ }^{3}$ On the one hand, the ADF was annihilated and has ceased any significant military activity within Uganda since 2004. On the other hand, in March 2002, the army launched a large-scale offensive, named "Operation Iron Fist", against the LRA bases in South Sudan. The LRA responded by attacking many villages and the government forces in Northern Uganda. Both fighting sides appear to have exercised brutal violence against civilians (Finnström 2008). Military activity and reprisals peaked in 2003, then the rebel activity declined considerably as of 2004. In 2005, the LRA was forced to move its bases to the Democratic Republic of Congo, while the International Criminal Court issued arrest warrants for Joseph Kony and other LRA commanders. A cease-fire between the LRA and the government of Uganda was signed on September 2006, with the mediation of the autonomous government of South Sudan. Negotiations about a permanent settlement continued in Juba (South Sudan). Although hopes were later frustrated by Kony's refusal to sign the peace agreement in 2008, LRA-related fighting in Uganda has been sporadic after 2006.

Figure 1 shows the total number of geo-referenced fighting events between 1997 and 2008 from Armed Conflicts Location Events Data (ACLED). Between 2000 and 2008 ACLED reports over 2600 fighting events. Consistent with the narrative above, there was a sharp escalation in 2002-05. This is followed by a decline, and very low levels of violence have been recorded since 2006. It is worth noting that the escalation of violence in 2002-05 is not merely an Acholi phenomenon. An increasing number of conflicts were recorded all over Uganda in this period (see Figure 2). This justifies studying the effect of conflict across all Uganda.

We are interested in measuring the effects of such fighting on different measures of trust and ethnic identity. To this aim, we exploit two waves of survey data from Afrobarometer 2000 and 2008, including information on socioeconomic characteristics at the individual level. ${ }^{4}$ The Afrobarometer is a repeated

\footnotetext{
${ }^{2}$ An example of this strategy is the Amnesty Act of 2000, by which the Government of Uganda granted amnesty to all rebels who would abandon violence, renouncing to criminal prosecution or punishment for offenses related to the insurgency.

${ }^{3}$ An additional factor was the end of the Second Congo War, which made it possible to the armed forces of Uganda to concentrate on the internal front.

${ }^{4}$ Although Afrobarometer also ran a survey in 2005, we decided to use the 2008 data, since the number of conflicts was still relatively large in 2005 (see Figure 1). Moreover, the number of people living as refugees was very large in 2005. This raises two issues. On the one hand, the hardship of life in refugee camps may be responsible for the low trust of respondents. On the other hand, although, as we document below, most camps were located close to people's village of residence, some people may have been displaced outside of their counties, rendering our identification strategy invalid. The problem is far less severe in 2008 .
} 


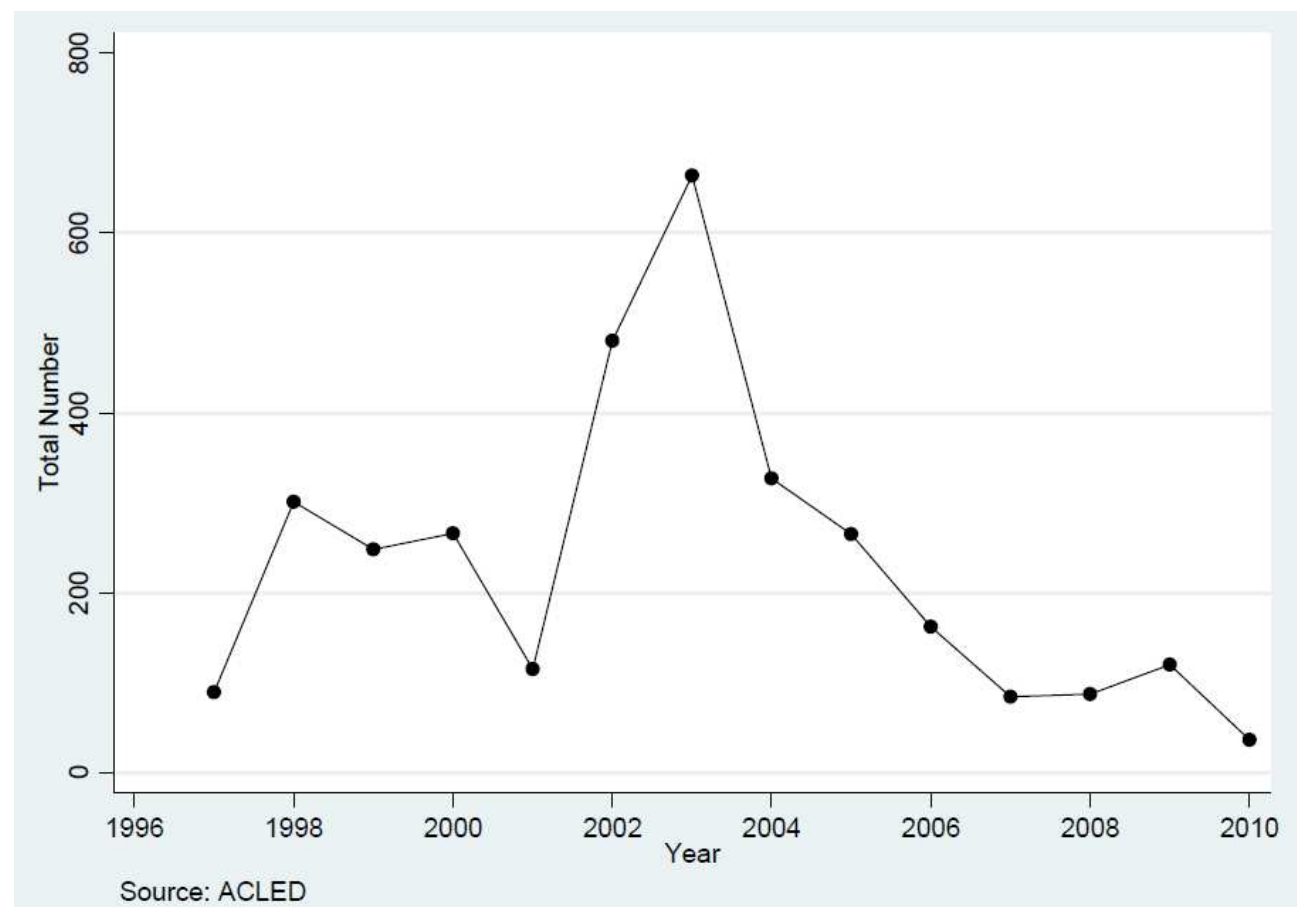

Figure 1: Number of Fighting Events Over Time in Uganda

cross section of individuals (a panel at the district-level). Our strategy is to regress individual measures of social capital in year 2008 on spatial measures of intensity of fighting during 2000-08, controlling for a large number of individual, ethnic and spatial characteristics. Most important, we control for the average social capital at the district level in 2000, in order to filter out the cross-district heterogeneity due to long-standing factors. ${ }^{5}$

We address concerns about reverse causality and omitted variables with two complementary strategies. First, we adopt an instrumental variables strategy. Our identification relies on an external political shock (i.e., the US enlisting the rebel movements of Uganda as a terrorist organization, and the Khartoum government withdrawing support to the LRA) affecting the intensity of fighting, but having no direct effect on trust measures. This political shock impacted the probability of fighting in a spatially heterogeneous way with a larger increase observed in high elevation areas and in Northern Uganda, and more specifically close to the Sudanese border. We use the county-level average distance from Sudan as a first instrument for the number of fighting events. We use the county-level maximum altitude as an additional instrument, since this also affects the probability of guerrilla activities (cf. Fearon and Laitin 2003; Collier, Hoeffler, and Rohner 2009). ${ }^{6}$

We also consider an alternative identification strategy relying on the within-county variation in

\footnotetext{
${ }^{5}$ The district of the respondent is the most disaggregated geographical information provided by the 2000 Afrobarometer

${ }^{6}$ Although both instruments are time invariant, our identification relies on the fact that such geographical characteristics affected the number of fightings in the post-2001 environment. So, in a sense, our instruments are the interaction between the 2001 political shock and the above mentioned geographic characteristics.
} 
conflict involving different ethnic groups. In particular, we exploit the information provided by ACLED identifying the rebel groups and ethnic militias involved in each single conflict event. When conflicts involve organized rebel groups, we map each rebel group or ethnic militia (whenever possible) to their main ethnic affiliation. Then, we regress measures of trust and identity on the number of conflict events involving different ethnic groups within each county, controlling for both county and ethnic group fixed effects. Our hypothesis is that respondents should be especially affected by events involving their own ethnic group. ${ }^{7}$

Our main finding is that fighting events have a negative and statistically significant effect on "trust towards other people from Uganda". The estimated effect is quantitatively large, and robust to instrumenting fighting events by distance to Sudan and altitude. A one-standard-deviation increase in fighting translates into a $47 \%$ standard deviation decrease in trust. The effect is stronger when fighting events involve the respondent's ethnic group. Fighting has smaller effects, instead, on "trust in known people" and hardly any effect on "trust in relatives". The findings suggest that fighting induces distrust mainly towards people outside the ordinary social network. Moreover, people living in counties experiencing more fighting report a large increase in a self-reported measure of "ethnic identity", i.e., they identify themselves more strongly with their own ethnic group relative to national Ugandan affiliation. This result is robust to the inclusion of county and ethnic group fixed effects. Moreover, the results are not driven by the Acholi region, the most tormented by the conflict between the LRA and the government. Excluding all counties of core Acholiland does not affect the estimates.

In Rohner, Thoenig and Zilibotti (2011), we argue that by undermining trust, conflict hinders economic cohesion in ethnically divided societies. A thorough empirical investigation of this question would require a longer time span of data. However, in the second part of the paper, we make a first step in this direction by extending the analysis to the economic effects of ethnic conflicts. Ideally, we would like to use county-level GDP per capita. However, such data are not available for Uganda. We resort to proxying them by using the subjective information contained in the Afrobarometer where people are asked an assessment of their own economic situation (the same question was asked in both 2000 and 2008, so we can control for the district-level economic situation in 2000). Since we use the Afrobarometer survey of 2008 (while, recall, most fighting events are in the period 2002-05), the responses are unlikely to reflect the direct economic effects of conflict, due to, e.g., destructions of villages or crops. We document an interesting interaction effect: for a given intensity of fighting, post-conflict economic recovery depends on the ethnic fractionalization at the local level. Fighting has a negative effect on the economic situation in highly fractionalized counties, but has less of an effect in less fractionalized counties. Since survey-based data about the economic situation are subject to perception biases, we repeat the analysis using an alternative proxy of the level of economic activity, i.e., the average intensity of light recorded by U.S. meteorological satellites during night for each county in Uganda in our years of interest.

\footnotetext{
${ }^{7}$ People may also respond to violence involving their own ethnic group outside of the district where they live. However, such events are likely to be observed less precisely. Interestingly, we find that people owning a radio also respond to out-of-district events involving the own ethnic group.
} 
The finding that violence that occurred mostly four-to-five years before the survey has a stronger effect on economic outcomes in ethnically fractionalized counties is consistent with the view that conflict hinders economic cooperation in ethnically divided societies. The evidence suggests that the effects of violence on social capital may have weaker effects on economic cooperation when violence does not involve ethnic cleavages. Therefore, violence may have more persistent effects in an ethnically divided society.

\section{$1.1 \quad$ Related literature}

This paper is part of a large literature on inter-ethnic conflict. Several seminal contributions in the literature link explanations of ethnic turmoil to characteristics of the political process (cf. Horowitz 2000; Gurr 1993, and Varshney, 2003), while most recent formal theories focus on the effect of the exogenously given population composition (see, e.g., Esteban and Ray 2008, 2011, and Rohner 2011). Relative to these papers, our study suggests that ethnic identity may be endogenous relative to the conflict dynamics. $^{8}$

While our study focuses on the effect of conflict on social capital, a large empirical literature has studied over the last decade the opposite channel, i.e., how different measures of ethnic diversity predict the outbreak of civil wars. ${ }^{9}$ However, there is also a growing number of micro-level studies dealing with the impact of conflicts on human capital. Matching household survey data with information on local war intensity, some papers document that war experience reduces the educational attainment of the cohorts exposed (cf. Swee 2008 for Bosnia; Leon 2009 for Peru; Akresh and de Walque 2010 for Rwanda; Shemyakina 2010 for Tajikistan). Blattman and Annan (2009) find that former abductees in Uganda have lower education and lower salaries later in life, as well as more psychological distress. There is also a literature in medicine, finding that child soldiers or children who experienced war are much more likely to experience depression, post-traumatic stress or anxiety in the months and years after the event. ${ }^{10}$

\footnotetext{
${ }^{8}$ In this sense our paper is related to a small literature studying endogenous ethnic identity in contexts that are very different. Fryer and Levitt (2004) show that the intensity of "black" identity in the United States and the use of distinctively black names have varied widely over time, peaking during the period of the Black Power movement.

In a development context, Posner (2004) studies the relations between the Chewas and Tumbukas across the border between Malawi and Zambia. He shows that although the objective differences between these two groups are the same on both sides of the border, in Malawi the relations between these two ethnic groups are very hostile and filled with distrust, while in Zambia they are close allies. His explanation is that this is because in Malawi the groups are large enough relative to the other groups in the country for being mobilized politically, whereas in Zambia they are both small players that cooperate together.

Caselli and Coleman (2011) present a theory of ethnic conflict where the composition of ethnic groups is endogenous, as people can switch groups.

Balcells (2011) finds that victimization during the Spanish civil war has had a persistent impact on the victims' political identities (i.e., left-right).

Our paper is also related to the theoretical literature on the emergence of parochial altruism and strengthened withingroup ties in environments characterized by frequent inter-group conflicts (cf. Bowles and Gintis 2004; Choi and Bowles 2007).

${ }^{9}$ See Fearon and Laitin (2003), Collier and Hoeffler (2004), Collier and Rohner (2008), Collier, Hoeffler and Rohner (2009), Montalvo and Reynal-Querol (2005) and Esteban, Mayoral and Ray (2011).

${ }^{10}$ See Dyregrov et al. (2000); Dyregrov, Gjestad and Raundalen, (2002); Barenbaum, Ruchkin and Schwab-Stone
} 
The studies above focus on human rather than social capital. More directly related to our work is the recent literature on the effect of individual war experience on political participation and local collective action. In particular, Bellows and Miguel (2009) use a household survey and analyze whether people who have been victimized in the civil (but not ethnic) war in Sierra Leone are affected in their post-war behavior. In particular, they find that more victimized people are more likely to "attend community meetings" and "join social and political groups". Related research focuses on the reintegration of former child soldiers. The study of Blattman (2009) on Northern Uganda finds that young men who have been abducted and forced into joining rebel forces are subsequently more prone to vote and engage in local community action. Humphreys and Weinstein (2007) find that past participation in abusive military fractions makes reintegration in society harder in Sierra Leone. Further, ideologues, men and younger fighters have more problems reintegrating than other ex-combatants. Besley and Reynal-Querol (2012) study the historical legacy of pre-colonial conflict in Africa and find that historical conflict is negatively correlated with trust levels today.

There is also a related literature based on lab and field experiments. Whitt and Wilson (2007) make Bosnians play the dictator game and find that players treat opponents from the same ethnic group with more fairness. Voors et al. (2010) find that players who have been exposed to more violence in their past behave more altruistically to neighbors and are more risk seeking. Gilligan, Pasquale and Samii (2010) find that communities with greater exposure to violence during the civil war in Nepal exhibit more social capital in behavioral games. ${ }^{11}$ Cassar, Grosjean and Whitt (2011) run experiments in Tajikistan and find that conflict exposure reduces trusting and fair behavior to a larger extent in interactions with other players from the same area than with people from elsewhere. They explain this finding by the nature of the Tajik war, where clear frontlines were absent and where there was much violence within villages. To check whether war exposure breeds aggressive behavior in the future, Miguel, Saiegh and Satyanath (2011) study the behavior of foreign players in the main professional soccer leagues in Europe, finding that indeed past civil war exposure correlates with the number of yellow and red cards received.

Our paper is also related to the literature linking trust and social capital in communities to past history and ethnic fragmentation. ${ }^{12}$ While Alesina and La Ferrara (2000) find that participation in social activities is lower in ethnically heterogeneous communities, the same authors show in a later paper that a recent history of traumatic experiences and discrimination, poverty, low education, ethnic diversity, and economic inequality correlate with low trust (Alesina and La Ferrara 2002). ${ }^{13}$ Using Afrobarometer and various historical data, Nunn and Wantchekon (2011) find that individuals living in

(2004); Derluyn et al. (2004); Kohrt et al. (2008).

${ }^{11}$ Fearon, Humphreys and Weinstein (2009) find that in post-conflict Liberia donor's efforts to organize the distribution of aid in community-driven and democratically administered projects can contribute to partly reconstruct the destroyed social cohesion of society.

${ }^{12}$ For a general discussion of the origins and effects of trust and social capital, see the survey articles of Guiso, Sapienza and Zingales (2006) and Fehr (2009). See also Putnam, Leonardi and Nanetti (1993), Dasgupta (1988, 1999) and Sobel (2002).

${ }^{13}$ Related to this, Alesina and Zhuravskaya (2011) find that more ethnically and linguistically segregated countries have a lower quality of government. 
sub-Saharan African countries whose ancestors belonged to tribes that were subject to a high intensity of enslavement report lower trust levels today. Our results are complementary to theirs. While they emphasize persistent effects of events that occurred long time ago, we show that large contemporaneous shocks can indeed change beliefs and social capital. In a similar vein, Guiso, Sapienza and Zingales (2009) document that bilateral trust across countries depends on the number of years in which the two countries have been in war during the last millennium. Algan and Cahuc (2010) use inherited trust of descendents of US immigrants to identify the causal effect of trust on economic growth around the world, while Giuliano and Spilimbergo (2009) study the other direction of causality, finding that growing up during a recession persistently depresses confidence in public institutions.

Moving to business links, Fafchamps (2000) and Fisman (2003) find that African firms are more likely to obtain supplier and bank credit from firms associated to the same ethnic group. Macours (2004) shows that in the Guatemalan land rental market - where property rights are mostly absent and ethnic tensions are strong- landlords are more likely to rent out to tenants from the same ethnic group. These papers are related to the findings in our paper that fighting appears to have larger post-war economic effects in ethnically fractionalized counties. Although we have no direct measure of inter-ethnic business links, our results are consistent with the hypothesis that inter-ethnic business links are more sensitive to disruptions associated with the collapse of social capital, and thus ethnically fractionalized counties suffer larger economic consequences after fighting.

Finally, our paper is related to the limited literature on the consequences of the conflict in Uganda. Aside from the papers already mentioned above, a closely related work to ours is Bozzoli, Brueck and Muhumuza (2011), who analyze the effect of conflict on individual expectations in Northern Uganda. Their paper is complementary to ours insofar as it documents the effect of differential exposure to conflict. However, they use a different dataset (the Northern Uganda Livelihood Survey) which only covers the population living in six Northern districts. This survey is only available for 2007, so preconflict attitudes cannot be controlled for. Most important, their study focuses on a psychological dimension rather than on trust. In particular, they show that exposure to conflict affects negatively people's optimism about future perspectives. A recent paper by De Luca and Verpoorten (2011) which is posterior to the first version of our paper and which was carried out independently - studies the effect of conflict in Uganda on associational membership and trust. There are a number of differences between the two studies, concerning both the methodology and the focus of the contributions. They use a different econometric specification which does not control for past trust (which is important in our identification), nor do they consider ethnic identity. They do not link fighting events to specific ethnic groups, whereas an important part of our contribution is to study the variation in ethnic violence involving different groups within each district. Finally, our study considers persistent economic effects of ethnic violence on living conditions, whereas theirs does not. Deininger (2003) analyzes household survey data for Uganda and finds that households that were more heavily affected by civil strife are less likely to engage in (non-farm) enterprise expansion or startup and are more likely to close down an existing enterprise. Vargas Hill, Bernard and Dewina (2008) document that in Uganda agricultural 
"cooperatives were much less likely (...) to exist in communities that had recently experienced civil conflict". Finally, Collier (1999) finds that transaction and capital intensive sectors like construction, transports, finance, and manufacturing suffered relatively more from the war in Uganda than less vulnerable sectors like subsistence agriculture.

Section 2 provides an overview of the historical context of the Ugandan conflict. Section 3 describes the data and empirical strategy. Section 4 discusses the main empirical results regarding the effect of conflict on various measures of trust and ethnic identity. Section 5 analyzes the economic effects of ethnic conflict. Section 6 concludes. A number of additional statistics and robustness tests are in the Appendix.

\section{Context of Conflict in Uganda}

Already in pre-colonial times the area of what is Uganda today has been ethnically very heterogeneous, with the main division being between the people of the North who are part of the broader ethnic category of "Nilotes", while the South has been occupied by people belonging to the "Bantu" ethnic category. ${ }^{14}$

The ethnic identities were fostered by the British colonization as part of a divide-and-rule strategy. In particular, the colonial administration restricted inter-ethnic movements, and "colonial practices were powerful instruments in the making of more rigid ethnic boundaries and divides in Uganda" (Finnström, 2008: 38). This is confirmed by Nannyonjo (2005), arguing that the British encouraged the divisions between the North and the Bantu-dominated South. While the Nilotic tribes (and in particular the Acholi tribe) were over-represented in the army, they were under-represented in the administration and white-collar jobs, and generally discriminated (Nannyonjo 2005).

Even after independence in 1962, Ugandan politics remained dominated by ethnicity, and each leader favored some tribes, and repressed others. "Uganda's first prime minister, Milton Obote, was overthrown by his army commander Idi Amin in 1971. During Amin's regime (1971-79) Langi and Acholi soldiers, perceived to be Obote's agents, were treated harshly" (Nannyonjo 2005: 475). After Amin, it was again the turn of Obote to rule the country, who was followed by Acholi officer Tito Okello. During this period, the dominant position of northerners in the army was reinstalled, only to be dismantled again when Okello lost power in 1986 to the former rebel leader of the National Resistance Army (NRA) and current President of Uganda, Yoweri Museveni, who is a southerner (Finnström 2008). ${ }^{15}$ The northerner (and in particular, Acholi) ex-officers and soldiers of the Ugandan army who fell from grace under Museveni have since then been important components of the various Northernbased rebel movements of the last decades. "In April 1987 Joseph Kony started his own military movement by drawing support mostly from the Acholi UPDA deserters" (Nannyonjo 2005: 476). This

\footnotetext{
${ }^{14}$ The following discussion of the context of the Ugandan conflict draws heavily on Nannyonjo (2005) and Finnström (2008).

15 "Okello's military junta of Acholi-dominated forces withdrew to their homelands in northern Uganda and later to Sudan, where they formed the Uganda People's Democratic Army (UPDA) to oppose the NRA" (Nannyonjo 2005: 476-7).
} 
movement eventually became in 1994 the most important and persistent rebel movement of Uganda, under the name of Lord's Resistance Army (LRA).

Although the LRA has increasingly multiplied criminal activities and often attacked also people from their own ethnic background accused of being traitors, the conflict has a clear ethnic dimension. On one side, there are the northern combatants that used to represent the official army and are now considered rebels, and on the other side there are the southern fighters of Museveni who used to be rebels and now represent the official Ugandan army. ${ }^{16}$ According to Nannyonjo (2005: 475), "the current conflict in the Acholi and Lango sub-regions between the LRA and the Ugandan government has deep historical roots resulting from ethnic hostilities, colonial-era marginalization of the north, institutional weaknesses, troubled politics during the post-independence period when military sectors of different ethnic groups aspired to regain power from a succession of Ugandan governments, and from certain external factors". As expressed by Finnström (2008: 74-75), "the majority of people in central Uganda perceived Museveni's war as a war against a regime of northerners, rather than the war for democracy. (...) While he was a guerrilla leader, Museveni sometimes propagated Bantu commonality in an effort to strengthen local support in the immediate war zone. (...) In Museveni's war propaganda, the enemy was alleged to be northerners in general and Acholi in particular". In the words of the Women's Commission (2001: 81), "the current conflict in northern Uganda has its roots in ethnic mistrust between the Acholi people and the ethnic groups of central and southern Uganda as well as in the religious and spiritual beliefs of the Acholi people and the manipulation of these beliefs." And this distrust has persisted, as "still today it is common for people in Kampala and beyond to regard people from northern Uganda as backward and martial" (Finnström 2008: 79).

Interestingly, even if the northern population suffers not only from large-scale violence and abuse of the southern government troops (Dolan 2009) ${ }^{17}$, but is also repeatedly targeted by the LRA, the primary blame and grievances are still directed against the government in Kampala and the southern Bantu-speaking tribes that it represents. "The more violence the rebels commit against the noncombatant population, the more the government will be blamed by the same exposed people for its failure to protect and provide for its citizens. A growing number of young people feel that the war increasingly excludes them from the various modern developments in Uganda" (Finnström 2008: 129).

The role of Sudan is especially important. Since the early 1990s, the Khartoum government had provided the LRA with logistic support and military equipment, allowing its base camps in southern Sudan. In exchange, the LRA helped the Sudanese army to fight against the south Sudanese rebels. The Ugandan government, in turn, supported the Sudan People's Liberation Army (Finnström 2008: 84-85). Reciprocal accusations led the two governments to cut diplomatic relationships in 1995,

\footnotetext{
${ }^{16}$ According to Finnström (2008) the Museveni government has tried hard to frame the Lord's Resistance Army as unpolitical criminals who attack their own people. In particular, "the rhetoric of a local northern conflict in which Acholi kill fellow Acholi like cannibalistic grasshoppers, reflects a more general Ugandan conception of the Acholi as violent and war-prone" (Finnström 2008: 107).

${ }^{17}$ According to Finnström (2008: 71), "in northern Uganda, it turned out that the conduct of the Museveni's troops (...) soon deteriorated. Killings, rape, and other forms of physical abuse aimed at noncombatants became the order of the day soon after the soldiers established themselves in Acholiland, which was foreign territory for them".
} 
allegedly because of Sudan's support for the LRA in retaliation for the government of Uganda's involvement in the Sudanese government's war against the Sudan People's Liberation Movement/Army (SPLM/A). In early 1999, the former US President Jimmy Carter chaired negotiations to restore diplomatic relations (see Neu 2002). Progress was slow, until an acceleration occurred after September 11, 2001, when the Sudanese government was under heavy pressure for its support to Islamic radicalism. In 2002 Uganda and Sudan restored diplomatic relations and signed a protocol which gave the Ugandan army the right to enter southern Sudan and attack the LRA.

Besides this major violent conflict between the southern government and the northern rebels of the Lord's Resistance Army, there have been in recent years several other smaller-scale ethnic conflicts in Uganda. For example, the rebels of Allied Democratic Forces (ADF) have been fighting the government in southwestern Uganda, while there has been wide-spread tribal violence in the northeastern Karamoja region, triggered by cattle raiding (Nannyonjo 2005; Finnström 2008).

\section{Econometric Analysis}

\subsection{Data Sources}

The backbone of our dataset is the Afrobarometer 2008 survey on Uganda, in which 2431 subjects were surveyed between July and October 2008, in 55 districts and 125 counties of Uganda. ${ }^{18 ; 19}$ Each respondent is associated with a district and county of residence, as well as with an ethnic group. We also use information from Afrobarometer 2000. Note that the finest geographical unit included in the 2000 survey is the district. Thus, we can only construct our control variables from this data source (particularly, past trust and living conditions) at this level.

The other main data source is the ACLED (Armed Conflict and Location Event Data, 2011) dataset that provides precise geo-location of various categories of fighting events. However, in Afrobarometer, we ignore the precise geolocalization of respondents. Using ArcGIS, we consequently aggregate fighting events both at the county- and district-level and match them with the county and district of residence of Afrobarometer respondents.

All variables are described in detail in the Data Appendix, and the descriptive statistics of all variables used are contained in Table 18 in the Appendix. We describe hereby the main variables.

\footnotetext{
${ }^{18}$ Afrobarometer selects samples in the following way: "The sample is designed as a representative cross-section of all citizens of voting age in a given country. The goal is to give every adult citizen an equal and known chance of selection for interview. We strive to reach this objective by (a) strictly applying random selection methods at every stage of sampling and by (b) applying sampling with probability proportionate to population size wherever possible (...). The sample is stratified by key social characteristics in the population such as sub-national area (e.g. region/province) and residential locality (urban or rural)" (Afrobarometer 2011).

${ }^{19}$ In Uganda, there are 78 districts which are divided up into 146 counties. The average population of a district in 2009 is about 410000 , whereas that of a county is 219000 .
} 


\subsection{Main Variables}

Dependent variables: We use five questions from Afrobarometer 2008 and construct the following dependent (binary) variables at the individual level:

- Generalized trust: "How much do you trust each of the following types of people: Other Ugandans?" (question Q84C). The variable takes the value one if the respondent answers either "I trust them somewhat" or "I trust them a lot". Otherwise, the value is set to zero. In one of our robustness checks we show that our estimates are not sensitive to changes in this binarization procedure.

- Trust in Known People: "How much do you trust each of the following types of people: Other people you know?" (question Q84B). The variable takes the value one if the respondent answers either "I trust them somewhat" or "I trust them a lot". Otherwise, the value is set to zero.

- Trust in relatives: "How much do you trust each of the following types of people: Your relatives?" (question Q84A). The variable takes the value one if the respondent answers either "I trust them somewhat" or "I trust them a lot". Otherwise, the value is set to zero.

- Ethnic identity: "Let us suppose that you had to choose between being a Ugandan and being a _ [R's Ethnic Group]. Which of the following best expresses your feelings?" (question Q83). The variable takes the value one if the respondent answers either "I feel only (R's ethnic group)" or "I feel more (R's ethnic group) than Ugandan". Otherwise, the value is set to zero.

In section 4 we denote our dependent variable by $T R U S T^{08} \in\{$ Generalized trust, Trust in Known People, Trust in relatives, Ethnic identity\}. In section 5, we run two regressions where the dependent variables are proxies for the level of economic activity. The first such variable is also from Afrobarometer 2008:

- Living conditions: "In general, how would you describe: Your own present living conditions?" (question Q4B). The variable takes the value one if the respondent answers either "Neither good nor bad", or "Fairly good", or "Very good". Otherwise, the value is set to zero.

The second such variable (Satellite light) is a measure of the light intensity during night from the Satellite Nightlight Data from the National Oceanic and Atmospheric Administration (2010). These data have been used in recent research as a proxy for economic activity (see, e.g., Henderson, Storeygard, and Weil 2011, and Hodler and Raschky 2011).

Main explanatory variables: We use four alternative explanatory variables with variation at the county-level (at the district-level in several specifications), FIGHTING $G_{c}^{00-08} \in\{$ All Fighting, Violence Against Civilians, Battles, Internally Displaced People\}. All variables code fighting events taking place between the last day of the Afrobarometer 2000 survey (on June 26, 2000) and the first day of the Afrobarometer 2008 survey (on July 27, 2008) 
- All Fighting (main explanatory variable): Total amount of all violent events in a county. It corresponds to the sum of the events of the following "Event Type" in ACLED: "BattleGovernment regains territory", "Battle-No change of territory", "Battle-Rebels gain territory", "Riots/Protests", and "Violence against civilians".

- Violence Against Civilians: Total number of events coded as "Violence against civilians" in ACLED.

- Battles: Total number of events coded as "Battle-Government regains territory", "Battle-No change of territory", and "Battle-Rebels gain territory" in ACLED.

- Internally Displaced People (IDP): Total number of internally displaced people per district in 2006 from UNHCR (2006).

In an alternative specification (section 4.8), we use the information provided by ACLED to match (whenever feasible) each event coded in All fighting to a particular ethnic group according to the classification of Afrobarometer 2008 (Q79). In this alternative specification, All fighting varies on the ethnic group level, and corresponds to the total number of violent events linked to a tribe.

Primary control variables: We define as "primary" control variables the ones that have a key role in our identification strategy, since (as explained below) they allow us to filter out heterogeneity in the pre-treatment stage. The first component is a vector of trust/identity variables from Afrobarometer 2000, denoted by $\mathbf{T R U S T}^{\mathbf{0 0}}=\{$ Generalized trust 2000, Trust in Known People 2000, Trust in relatives 2000, Ethnic identity 2000\}. The variation of $\mathbf{T R U S T}^{\mathbf{0 0}}$ is at the district level. The second component is a scalar, Slavery, with variation at the ethnic group level. Slavery is borrowed from Nunn and Wantchekon (2011). It measures the number of people who were enslaved during the nineteenth century in each ethnic group, normalized by the area of land inhabited by the group. This is their preferred measure of incidence of slave trade.

The questions asked in Afrobarometer 2000 were not identical to those asked in Afrobarometer 2008. The exact construction of the 2000 variables is deferred to Appendix B. In section 5, the dependent variable is Living condition, and we control for its analogue in year 2000.

Other control variables: All regressions include a vector of individual sociodemographic controls (X) from Afrobarometer 2008, consisting of age, education, employment status, gender, rural/urban location, religion and ownership of a radio and of a TV; and a vector of district-level controls $(\mathbf{Z})$ including population, urbanization rate, demographic structure, share of manufacture, share of subsistence farming, net migration, fertility, number of micro-enterprises, and unemployment, which are all from the Census of the Ugandan Bureau of Statistics (2002). These data are not available at the county level. Information on elevation is from a geo-referenced shape-file produced by Hijmans Lab at UCDavis (2010). Finally, we use the Geo-Referenced Ethnic Group (GREG) dataset, which allows us to compute ethnic fractionalization measures on the county levels (Weidmann, Rød and Cederman 2010). 


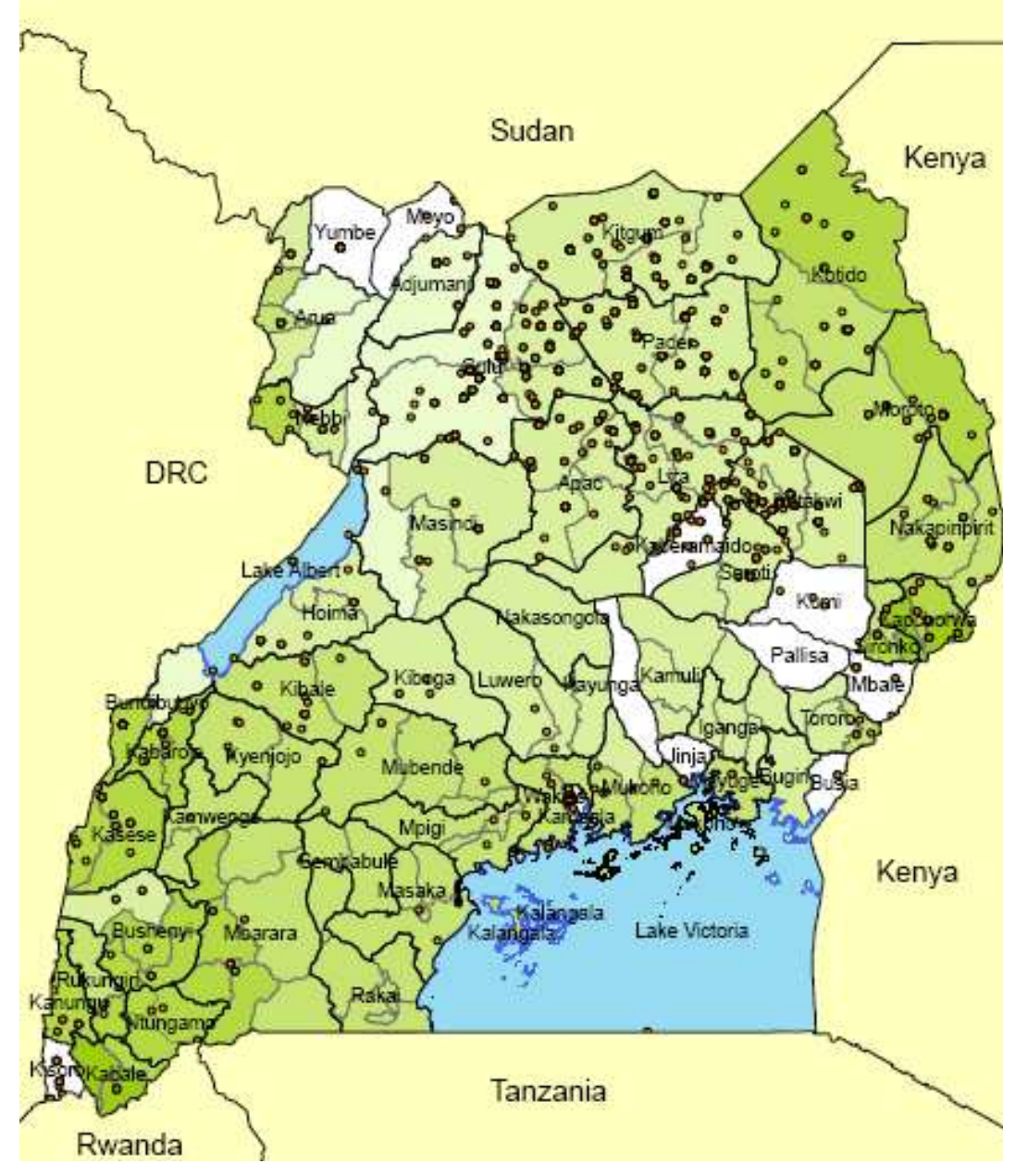

Figure 2: Map of Uganda (red dots=conflict events, darker green=higher altitude). Sources: ACLED (2011) and Hijmans Lab at UCDavis (2010). 


\subsection{Empirical Strategy}

We consider the following benchmark econometric model:

$\operatorname{Pr}\left(T R U S T_{i, c, e}^{08}=1\right)=\Phi\left[a_{0}+a_{1} F I G H T I N G_{c}^{00-08}+a_{2}\right.$ Slavery $\left._{e}+\mathbf{T R U S T}_{d}^{\mathbf{0 0 \prime}} \boldsymbol{\beta}+\mathbf{X}_{i}^{\prime} \boldsymbol{\gamma}+\mathbf{Z}_{d}^{\prime} \boldsymbol{\delta}+u_{i, c, e}\right]$

where $i$ denotes an individual, $c$ a county (where a county is a sub-unit of a district, $d$ ), and $e$ an ethnic group.

We will estimate (i) Probit maximum likelihood models and (ii) linear probability models using either the ordinary least square (OLS) or the two-stage least squares (2SLS) estimator, in presence of instrumental variables. Hence, $\Phi$ in equation (1) is either the $c d f$ of a standard normal distribution (in the Probit model) or the identity function. $T R U S T^{08}$ yields the different measures of trust/identity from Afrobarometer 2008. FIGHTING $G_{c}^{00-08}$ is our main explanatory variable, as discussed above. In the set of tables below, we always report the estimated coefficient $a_{1}$ capturing the effect of county-level fighting on trust/identity. In alternative specifications we change the scale of analysis by considering FIGHTIN $G_{d}^{00-08}$, a measure of fighting at the district-level rather than at the county-level.

The primary control variables TRUST $^{\mathbf{0 0}}$ (a vector) and Slavery (a scalar) are designed to filter out heterogeneity in the pre-treatment measures of trust at the geographic or ethnic group level. They play a key role in our identification strategy. Ideally, since our aim is to identify the causal effect of shocks taking place between the two Afrobarometer surveys, we would like to control for individual measures of trust in 2000. However, this is not possible since Afrobarometer is not a panel at the individual level. Filtering out the effect of past trust at the district level, TRUST $^{\mathbf{0 0}}$ yields the best approximation to such an ideal specification. Since part of the time-invariant heterogeneity may be rooted at the ethnic rather than at the geographical level, we filter out heterogeneity in long-term trust across ethnic groups by controlling for Slavery following Nunn and Wantchekon (2011) who show that it has a large and significant explanatory power on the average level of trust exhibited by people belonging to different ethnic groups in Afrobarometer 2005.

We introduce a set of additional individual sociodemographic control variables $\left(\mathbf{X}_{i}\right)$ and districtlevel controls $\left(\mathbf{Z}_{d}\right)$ to filter out additional sources of heterogeneity (with a slight abuse of notation, we include ethnic fractionalization in the vector $\mathbf{Z}_{d}$, although it is measured at the county level). All district-level controls are from the Census 2002, and are therefore measured before the outburst of conflict in 2002-05. This reduces concerns about their endogeneity.

In all specifications we allow for intracluster correlation of the error terms $u_{i, c, e}$ both in the spatial and ethnic dimensions.

OLS and Probit regressions might yield inconsistent estimates of $a_{1}$, due to either reverse causality or omitted variables bias. We address this concern by an instrumental variable strategy. The concern for reverse causality is mitigated by the fact that our dependent variable is measured in 2008, three years past the end of active fighting. This is one of the reasons why we do not focus on Afrobarometer 2005, which surveys Ugandan people while fighting is either still ongoing or a very recent experience 
(see Figure 2). However, reverse causality cannot be completely ruled out if variables are serially correlated. Perhaps more importantly, unobservable shocks occurring after year 2000 may be driving both trust and fighting. To this aim, we instrument $F I G H T I N G_{c}^{00-08}$ by a set of county-level geographic characteristics $\{G\}$ that are correlated with the fighting intensity, while having, plausibly, no direct effect on trust. We focus in particular on the Distance to Sudan and to the Maximum elevation of each county.

Distance from Sudan is a natural instrument, since Southern Sudan played a crucial role in the 2002-05 military escalation. In particular, before 2001 this region used to be a safe heaven for rebel movements - most notably for the LRA. However, the events following September 11 forced the Sudanese government to withdraw its support to the LRA and to let the Ugandan army attack the LRA bases in Sudanese territory. This triggered the response of the LRA with repeated incursions, looting and engagements with the army within the Ugandan territory. ${ }^{20}$

Maximum elevation is also a natural factor affecting fighting. Collier, Hoeffler, and Rohner (2009) have found that countries with a larger proportion of mountainous terrain are more amenable to fighting. They argue that this is because rebels benefit from hiding in rough terrain. Hence, in a setting of classic guerrilla warfare like in Uganda, where clear frontlines and an open battlefield are lacking, we expect fighting to be most intense in areas close to the rebels' hiding grounds.

Our exclusion restrictions require that the error term $u_{i, c, e}$ is uncorrelated with the two instruments. In this respect, it is important to remember that our primary control variables (TRUST ${ }^{\mathbf{0 0}}$ and Slavery) should filter out the long-run correlation between $\{G\}$ and potential omitted factors. For instance, if counties (or tribes) neighboring Sudan were less inclined to trust and cooperation, due to unobserved historical or cultural factors, such factors might have a direct effect on TRUST ${ }^{08}$. However, they would as well affect $\mathbf{T R U S T}^{\mathbf{0 0}}$, and as long as their influence has not changed after 2000 (other than due to fighting), the instruments would be uncorrelated with the omitted variables conditional on the observables - which include TRUST $^{\mathbf{0 0}}$. To the opposite, problems would arise if the error term included time varying shocks that are correlated with the geographical variables. An example might be a weather shock during the period 2000-08. However, we could not find evidence of any such major event. In section 4.8 below, we consider a more demanding identification where we control for ethnic and county-level fixed effects.

Finally, one might be concerned with conflict-induced migration: Some people may live in 2008 in different counties from those where they used to live at the time of the conflict, due to the massive forced population displacements that took place during the conflict. However, this concern appears to be of limited importance in our data. First, by 2008 the majority of displaced people had returned to their home villages (see UN 2009; UNHCR 2010). The concern might have been more severe in 2005, when the number of people living in refugee camps peaked at 1.8 millions. This is another reason

\footnotetext{
${ }^{20}$ If we had a longer span of data and a full dynamic model, the instrument would be the interaction between September 11 and "distance to Sudan". Note that "distance to Sudan" could have a direct permanent effect on trust (if, e.g., Acholi people trust less the Kampala government than people in the rest of Uganda). However, this effect is filtered out by $T R U S T_{d}^{00}$. See the discussion below.
} 
why to not use the information in Afrobarometer 2005. Second, most movements took place within counties. People were forced to move from rural areas to so-called "protected villages" established mostly in local trading centers (UNOCHA 2002, Médecins sans frontières 2004). As a result, crosscounty migration is altogether modest. Given that our main explanatory variable is also defined at the county-level, the results are unlikely to be contaminated by cross-county conflict-induced migration.

\section{Results}

Table 1 presents the main results of our benchmark estimation, in which the dependent variable is Generalized trust in 2008. All specifications control for the set of control variables discussed in the previous section. Robust standard errors are adjusted for two-way clustering at the ethnic and county level.

Consider, first, the effects of our primary control variables, $\mathbf{T R U S T}_{d}^{\mathbf{0 0}}$ and Slavery (coefficients not reported in Table 1). Generalized trust is highly positively correlated with its district-level counterpart in Afrobarometer 2000 (which is, recall, a component of the vector $\mathbf{T R U S T}_{d}^{\mathbf{0 0}}$ ): the regression coefficient of "Generalized trust 2000" ranges between 1.27 and 1.86 across the different specifications, and is always highly significant. Such a high autocorrelation is reassuring. The coefficient of Slavery is, as expected, consistently negative: individuals belonging to groups exposed to high enslavement in the eighteenth century report a lower Generalized trust in 2008, ceteris paribus. The point estimates range between -0.41 and -0.50 , being on the margin of standard levels of statistical significance (the p-values range between 0.053 and 0.15 across the different specifications). The fact that the effect of slavery is smaller than in Nunn and Wantchekon (2011) is not surprising, since our regressions control for trust in 2000 which filters out most of the long-term variation. Consistent with this interpretation, the coefficient of Slavery turns much larger in absolute value and becomes highly significant if we omit $\mathbf{T R U S T}_{d}^{\mathbf{0 0}}$ in the regression.

Column (1) reports the marginal effect of All fighting in a Probit regression. The estimated marginal effect is negative (-1.93) and highly significant: people living in high-fighting counties turned on average less trustful towards other Ugandans relative to year 2000. In column (2) we report the results of the same specification as in column (1) using a OLS regression. The coefficient of All fighting is similar to the marginal effect of the Probit model (-2.06). Columns (3)-(7) report the results from 2SLS regressions for the linear probability model. In Appendix A in Table 17 we report the results of the same set of regressions using IV-Probit, which are very similar. The coefficient of All fighting in the IV regression is -4.75 (column 3), more than twice as large in absolute value as its OLS counterpart, and highly significant. Including in column (4) a measure from the Afrobarometer of the individual perception of violence (Insecure) does not significantly alter the results. ${ }^{21}$ The result is robust to the

\footnotetext{
${ }^{21}$ The measure Insecure is based on the individual answers to the question "Over the past year, how often, if ever, have you or anyone in your family: Been physically attacked?"). In our main specification, we do not focus on this individual measure of insecurity, because it is heavily endogenous and subject to a problem of potential selection into victimization (as discussed by Bellows and Miguel (2009)). Yet, it is interesting that the result is robust to controlling
} 
alternative measures of fighting, including Violence Against Civilians (column (5)), Battles (column (6)), and Internally displaced people (column (7)). ${ }^{22}$ In Appendix A in Table 14 we show that the results of Table 1 continue to hold when the generalized trust variable is not coded as a binary variable, but left at its original ordinal scale, and when Ordered Probit regressions are run.

Altonji, Elder, and Taber (2005) suggest a procedure aimed to gauge the amount of selection on unobservable characteristics based on the amount of selection on the observed explanatory variables. This allows to assess how severe the omitted variable bias should be in order for the effect of fighting to be fully driven by unobserved characteristics. We follow here the implementation procedure used by Nunn and Wantchekon (2011). This amounts to running two regressions: one with a restricted set of control variables and one with a full set of controls. In our case the natural restricted set of controls includes the primary controls, $\mathbf{T R U S T} \mathbf{T}_{d}^{\mathbf{0 0}}$ and Slavery (i.e., we exclude $\mathbf{X}_{i}$ and $\mathbf{Z}_{d}$ ). Then, we calculate the ratio $\left|\hat{a}_{1}\right| /\left(\left|\hat{a}_{1}^{R}\right|-\left|\hat{a}_{1}\right|\right)$, where $\hat{a}_{1}$ is the estimated coefficient with the full set of controls (column (2) in Table 1), while $\hat{a}_{1}^{R}$ is the estimated coefficient with the restricted set of controls. We obtain $\hat{a}_{1}^{R}=-1.02$, implying that $\left|\hat{a}_{1}^{R}\right|<\left|\hat{a}_{1}\right|$ (since $\hat{a}_{1}=-2.06$ ). Given that the point estimate is not attenuated, and even strengthened, by the inclusion of the full set of controls, selection on unobservables does not appear to explain our result (if anything, our result would be strengthened if the unobservables could be controlled for). ${ }^{23}$

\subsection{First stage regression}

Panel (a) of Table 2 reports the coefficients of the excluded instruments in the first-stage regressions of 2SLS specifications from Table 1 (columns 3-7). In all cases the IV coefficients are highly significant with the expected sign. All first stage regressions pass the Hansen overidentification test. Robust (Kleibergen-Paap) F-statistics accounting for clustered residuals are large, and always above the conventional threshold for weak instruments. One should however recall here that the standard Stock-Yogo critical values for weak instruments are constructed for the case of i.i.d. residuals, and do not apply to the case of clustered standard errors (see, e.g., Bun and de Haan, 2010). Therefore, the F-statistics provide no precise diagnostic of the weak instrument problem.

As additional diagnostics, we follow the procedure suggested by Angrist and Pischke (2009: 21213). Panel (b) of Table 2 reports the coefficient of All fighting in the second stage regression, along with a number of statistics of the first-stage regressions from a variety of specifications and estimation techniques. Column (1), reported for comparison, yields the benchmark second-stage estimate (column (3) in Table 1; column (1) in Panel (a)). Column (2) shows how the results would change if only the

for the individual perception of insecurity.

${ }^{22}$ We include IDP for two reasons: First, they are a proxy of fighting intensity. Second, forced displacements can be viewed as a deliberate military strategy in conflict (cf. Esteban, Morelli and Rohner 2011). Indeed, some authors see the protected villages for IDP in Uganda as part of an aggressive military strategy pursued by the Museveni government to control and oppress the civilian population in the North (Finnström 2008; Dolan 2009).

${ }^{23}$ Note, though, that the power of this robustness test depends on the explanatory power of the observable characteristics that are included. In our case, 16 out of the 33 additional control variables are significant at the 5 percent level and their inclusion increases the R-squared from 0.09 to 0.13 . 

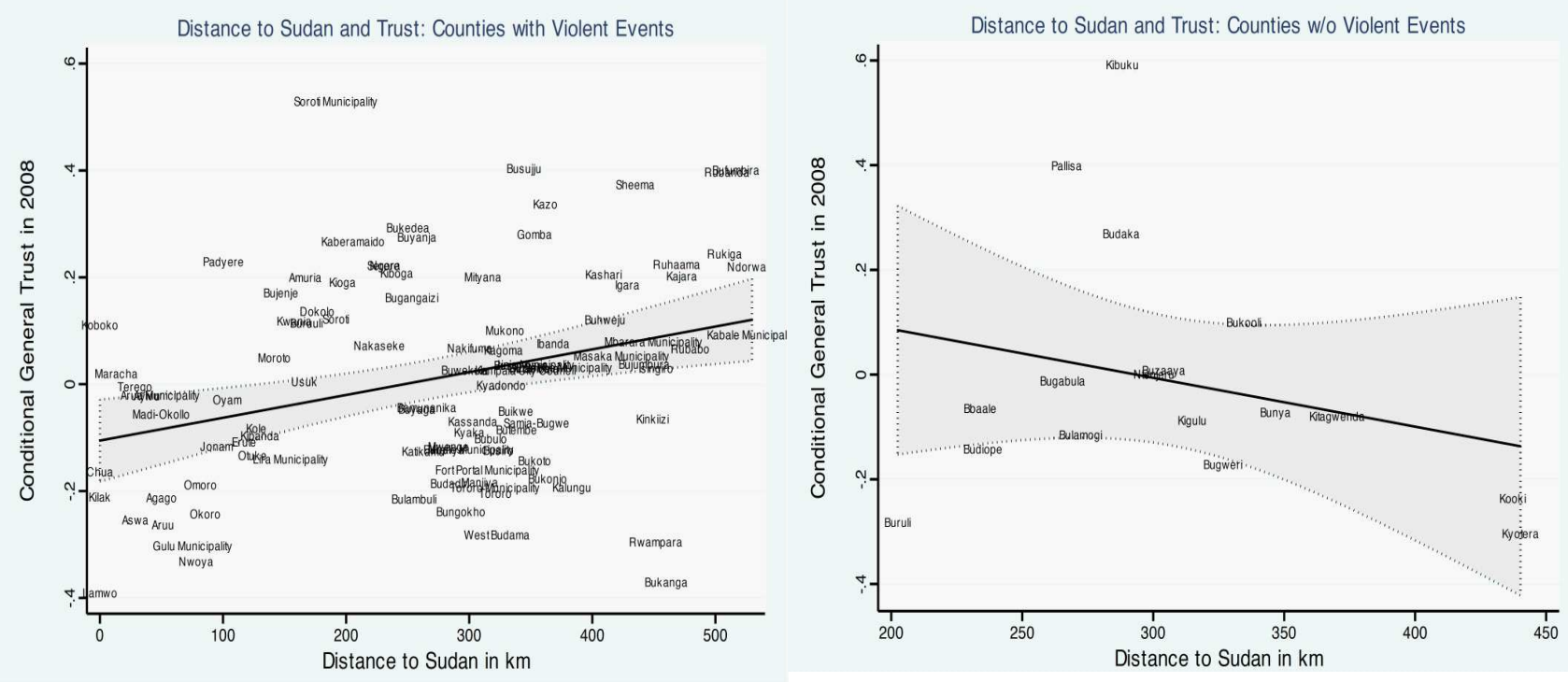

Figure 3: Distance to Sudan and Trust

most powerful instruments, Distance from Sudan, were retained, and the second instrument, Maximum elevation, were dropped. The estimated coefficient of All fighting remains significant at the $99 \%$ confidence level, while the F-statistics increases to 21. Next, in column (3) we use a LIML estimator. This estimator is less efficient but less subject to bias when instruments are weak. The fact that the results are almost identical to column (1) suggests no bias due to weak instruments. In column (4), we run a reduced-form regression. The coefficients of the two excluded instruments have the expected sign and are highly significant, which is again reassuring. Finally, in columns (5)-(6) we report the results of a specification where we collapse all variables to the county level. The results are similar to the benchmark specification using individual level variables. In this specification, standard errors are not clustered, allowing us to compute standard Cragg-Donald Wald F-statistics for i.i.d. residuals which can be compared to the Stock-Yogo bounds. We obtain $\mathrm{F}=8.9$ in the case in which both instruments are retained and $\mathrm{F}=12$ for the case with only one instrument. We conclude that our analysis is not subject to a weak instrument problem.

Figure 3 provides informal evidence about the plausibility of the exclusion restriction. The first panel considers counties characterized by a positive number of fighting episodes, while the second panel considers counties in which no fighting occurred. Each figure plots on the horizontal axes the distance from Sudan, and on the vertical axes the county-level average of generalized trust filtered by the set of control variables. Remarkably, the relationship is positive and highly significant across counties experiencing violence, while it is insignificant across those experiencing no violence. While this is by no means a formal test of the validity of our exclusion restriction, this falsification analysis is an interesting observation. 
Panel A

\begin{tabular}{c|ccccc}
\hline \hline Dep. var: & All fight. & All fight. & Viol. Civ. & Battles & IDP \\
\hline & $(1)$ & $(2)$ & $(3)$ & $(4)$ & $(5)$ \\
\hline Dist. from Sudan & $-0.12^{* * *}$ & $-0.12^{* * *}$ & $-0.05^{* * *}$ & $-0.07^{* * *}$ & $-0.96^{* * *}$ \\
& $(0.02)$ & $(0.02)$ & $(0.01)$ & $(0.02)$ & $(0.13)$ \\
Max. elevation & $0.01^{* * *}$ & $0.01^{* * *}$ & $0.00^{* *}$ & $0.01^{* * *}$ & $0.05^{* * *}$ \\
& $(0.00)$ & $(0.01)$ & $(0.00)$ & $(0.00)$ & $(0.01)$ \\
\hline Method & OLS & OLS & OLS & OLS & OLS \\
Observations & 2252 & 2252 & 2252 & 2252 & 2252 \\
R-squared & 0.775 & 0.775 & 0.747 & 0.722 & 0.908 \\
Hansen J stat: (p-value) & 0.96 & 0.92 & 0.35 & 0.54 & 0.14 \\
F stat. (Kleibergen-Paap) & 16.78 & 15.85 & 29.53 & 11.89 & 32.72 \\
\hline \hline
\end{tabular}

Note: Standard errors in parenthesis (robust, clustered at the county level). Significance levels * $\mathrm{p}<0.1, * * \mathrm{p}<0.05, * * * \mathrm{p}<0.01$.

Panel B

\begin{tabular}{|c|c|c|c|c|c|c|}
\hline \multirow[t]{2}{*}{ Dep.var: } & \multicolumn{6}{|c|}{ Generalized Trust in 2008 (Second stage) } \\
\hline & $(1)$ & $(2)$ & (3) & (4) & (5) & (6) \\
\hline All fighting & $\begin{array}{c}-4.75 * * * \\
(1.31)\end{array}$ & $\begin{array}{c}-4.81 * * * \\
(1.35)\end{array}$ & $\begin{array}{c}-4.75^{* * *} \\
(1.31)\end{array}$ & & $\begin{array}{c}-4.43^{* * *} \\
(1.58)\end{array}$ & $\begin{array}{c}-4.10 * * \\
(1.80)\end{array}$ \\
\hline $\begin{array}{l}\text { Dist. from Sudan } \\
\text { Max. elevation }\end{array}$ & & & & $\begin{array}{c}0.59 * * * \\
(0.18) \\
-0.07 * * * \\
(0.03)\end{array}$ & & \\
\hline Method & 2SLS & 2SLS & 2SLS (LIML) & OLS & 2SLS & $2 S L S$ \\
\hline Instruments & Sudan, elev. & Sudan & Sudan, elev. & $\mathrm{n} / \mathrm{a}$ & Sudan, elev. & Sudan \\
\hline Observations & 2252 & 2252 & 2252 & 2252 & 117 & 117 \\
\hline R-squared & 0.105 & 0.104 & 0.105 & 0.132 & 0.621 & 0.632 \\
\hline Hansen J stat ( $p$-value) & 0.96 & $\mathrm{n} / \mathrm{a}$ & 0.96 & $\mathrm{n} / \mathrm{a}$ & 0.73 & $\mathrm{n} / \mathrm{a}$ \\
\hline F stat. (Kleibergen-Paap) & 16.78 & 20.99 & 16.78 & $\mathrm{n} / \mathrm{a}$ & $\mathrm{n} / \mathrm{a}$ & $\mathrm{n} / \mathrm{a}$ \\
\hline F stat. (Cragg-Donald) & $\mathrm{n} / \mathrm{a}$ & $\mathrm{n} / \mathrm{a}$ & $\mathrm{n} / \mathrm{a}$ & $\mathrm{n} / \mathrm{a}$ & 8.87 & 12.01 \\
\hline
\end{tabular}

Table 2: First Stage of Benchmark Regressions (Panel A) and Robustness IV (Panel B). 


\subsection{Quantitative effects}

The magnitude of the estimated effects is large. ${ }^{24}$ The dependent variable, Generalized trust, has a sample mean equal to 0.31 with a standard deviation of 0.46 . All fighting ranges between 0 and 227 violent events with a standard deviation of 45 events. In table 1, an estimated coefficient of -4.75 in the 2SLS means that a one-standard-deviation increase in All fighting (i.e., 45 additional episodes of violence) translates into a $47 \%$ standard deviation decrease in generalized trust (i.e., a decrease in generalized trust of approximately 21 percentage points). With the more conservative OLS estimate we get that a one-standard-deviation increase in All fighting leads to a $20 \%$ standard deviation decrease in generalized trust; the "maximum" effect between counties with no violence and the county with the highest violence corresponds to a 45 percentage points decrease in trust towards other Ugandans. This is a very large effect, and is in the order of magnitude of the difference between the Netherlands (0.48), the eighth most trusting country in world, and the three countries with the lowest trust levels (Peru (0.05), Brazil (0.05); Philippines (0.06)). ${ }^{25}$ The quantitative effects are similar when alternative measures of violence are considered.

\subsection{Other dimensions of trust}

Table 10 (in Appendix A) is the analogue of Table 1 when the dependent variable is replaced by Trust in known people. The estimated effects of violence are smaller than in the case of Generalized trust (especially in the IV regressions), although they remain statistically significant.

In Table 11 (in Appendix A), the dependent variable is Trust in relatives in 2008. In this case, the effects are even smaller and become insignificant in the 2SLS regressions. This finding is partially different from Nunn and Wantchekon (2011), who find that a past history of enslavement has a negative effect on all dimensions of trust, including trust in relatives. This suggests that the effect of local ethnic conflicts is less pervasive and mostly confined to the inter-ethnic dimension.

\subsection{Ethnic identity}

To corroborate further the view that local ethnic conflicts impact inter-ethnic attitudes, we replace trust by a measure of Ethnic identity, gauging the extent to which respondents identify themselves with their ethnic relative to their national affiliation. Results are reported in Table 3. The estimated coefficient of interest is in all cases positive and significant. ${ }^{26}$ As in the case of Generalized trust, the coefficients in the 2SLS regressions are significantly larger than the OLS counterpart. In the 2SLS

\footnotetext{
${ }^{24}$ In all the tables, the fighting variables have been rescaled by a factor $10^{3}$ in order to improve readability of their estimated coefficients.

${ }^{25}$ These figures correspond to the average percentage of respondents answering "Most people can be trusted" to the World Values Survey Question A165 "Generally speaking, would you say that most people can be trusted or that you need to be very careful in dealing with people?". We use the average scores over the first three waves of the World Values Survey.

${ }^{26}$ We repeated the Altonji et al. (2005) procedure to detect problems of selection on unobservables. The restricted regression yields $\hat{a}_{1}^{R}=0.33$, whereas the coefficient in column $(2)$ is $\hat{a}_{1}=0.74$. Thus, again, selection on unobservables does not appear to drive our results.
} 


\begin{tabular}{|c|c|c|c|c|c|c|c|}
\hline & \multicolumn{7}{|c|}{ Dependent variable: Ethnic Identity in 2008} \\
\hline & (1) & (2) & (3) & (4) & (5) & (6) & (7) \\
\hline \multirow[t]{2}{*}{ All fighting } & $0.68^{*}$ & $0.74 * *$ & $2.86 * *$ & $2.60 * *$ & & & \\
\hline & $(0.36)$ & $(0.37)$ & $(1.19)$ & $(1.17)$ & & & \\
\hline \multirow[t]{2}{*}{ Insecure } & & & & $0.06 * *$ & & & \\
\hline & & & & $(0.03)$ & & & \\
\hline \multirow{2}{*}{ Violence Civil. } & & & & & $7.37^{* * *}$ & & \\
\hline & & & & & $(2.58)$ & & \\
\hline \multirow[t]{2}{*}{ Battles } & & & & & & $4.30 * *$ & \\
\hline & & & & & & $(1.93)$ & \\
\hline \multirow[t]{2}{*}{ IDP } & & & & & & & $0.43^{* * *}$ \\
\hline & & & & & & & $(0.14)$ \\
\hline Method & Probit & OLS & $2 S L S$ & $2 S L S$ & $2 S L S$ & $2 S L S$ & $2 S L S$ \\
\hline Observations & 2256 & 2259 & 2259 & 2259 & 2259 & 2259 & 2259 \\
\hline Pseudo R-squared & 0.056 & 0.059 & 0.040 & 0.048 & 0.040 & 0.042 & 0.060 \\
\hline
\end{tabular}

Note: The unit of observation is an individual. Robust standard errors in parenthesis (adjusted in all Probit regressions for clustering at county level, and in all OLS and 2SLS regressions for two-way clustering at county and ethnicity level).

Significance levels $* p<0.1, * * p<0.05, * * * p<0.01$. All specifications control for unreported individual sociodemographics (Age, Education, Employed, Gender, Rural, Own TV, Own Radio, 17 Religion Fixed Effects), districts characteristics at the beginning of the period (Past Generalized Trust, Past Trust in Own Group, Past Ethnic Identity, Population, Urbanization, Age-Dependency-Ratio, Share of Manufacture, Share of Subsistence Farming, Net Migration, Number of Micro-Enterprises, Adjusted Total Fertility Rate, Unemployment Rate), county characteristics (Ethnic Fractionalization), and ethnicity characteristics (Ln of Past Slave Exports per Area).

Table 3: Ethnic Identity.

regression, a one standard deviation increase in All fighting translates into a $32 \%$ standard deviation increase in ethnic identity (i.e. 12.8 percentage point). The estimated effect between the least and most conflictive districts is a 64.9 percentage point increase in ethnic identity. The quantitative effects are similar when alternative measures of violence are considered.

The first-stage regressions yield similar results to those discussed above for the case of generalized trust (see Appendix, Table 12). Concerning the falsification test, the two panels in Figure 4 show that the distance from Sudan is negatively correlated with the ethnic identity (conditional on the set of control variables) across districts experiencing violence, whereas the relationship is insignificant across districts experiencing no violence. Similarly to the case of trust, distance to Sudan appears to have an effect on ethnic identity only in the subsample of districts exposed to some fighting.

Finally, we note that in all the regressions discussed in this section the (unreported) coefficient of ethnic fractionalization does not appear to have a significant effect on trust or ethnic identity in 2008. This is not surprising, since there is little time variation in fractionalization, and any time invariant effect has been filtered out through controlling for measures of trust in 2000. More interesting, one could expect heterogeneous effects on trust depending on the extent of fractionalization. However, 

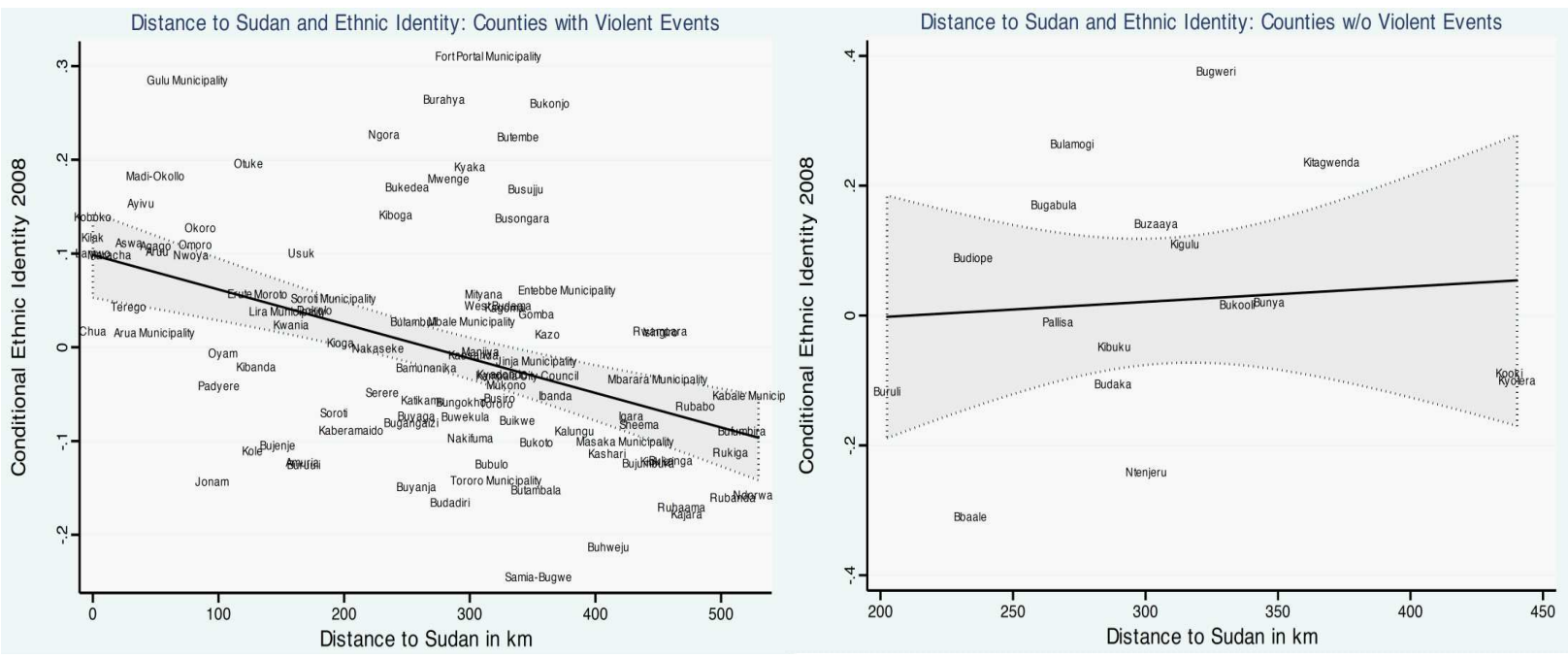

Figure 4: Distance to Sudan and Ethnic Identity

this is not the case, as an OLS specification with an interaction yields an insignificant coefficient.

In Appendix A in Table 17 we report the results of the same set of regressions as in this section but using IV-Probit, which are very similar.

The findings that conflict leads to a stronger ethnic identity and that it has a strong negative and significant impact on generalized trust, while having only a weak and non-significant effect on trust in family, is consistent with the theoretical literature on the emergence of parochialism and within-group bias in the face of inter-group conflict (cf. Bowles and Gintis 2004; Choi and Bowles 2007).

\subsection{Cross-district variations}

Tables 4 below and 15 (in the Appendix A) are the analogues of Tables 1 and 3 (for Generalized trust and Ethnic identity, respectively) when All fighting and the alternative measures of conflict are measured at the district rather than at the county level. Although this specification forgoes some information at a lower level of aggregation, this robustness check is important, since our primary control variables filtering out pre-treatment trust are measured at the district rather than at the county level. ${ }^{27}$

The results are very robust: all coefficients have the expected sign and remain significant at the 99\% level. In both specifications, the coefficients of All fighting and of the alternative measures of conflict are smaller. This is natural, since counties are smaller geographical units and informational frictions are likely to jam information about events happening far from the respondents' residence (recall that our fighting measures capture even minor events). Therefore, events occurring in the own county trigger a stronger response than events happening farther away in the same district.

\footnotetext{
${ }^{27}$ The cross-district specification was the main specification in the first draft of this paper (April 2011).
} 


\begin{tabular}{|c|c|c|c|c|c|c|c|}
\hline & \multicolumn{7}{|c|}{ Dependent variable: Generalized Trust in 2008} \\
\hline & $(1)$ & (2) & $(3)$ & (4) & (5) & $(6)$ & (7) \\
\hline \multirow[t]{2}{*}{ All fighting } & $-1.12 * * *$ & $-1.12 * * *$ & $-1.48 * * *$ & $-1.41 * * *$ & & & \\
\hline & $(0.24)$ & $(0.22)$ & $(0.38)$ & $(0.38)$ & & & \\
\hline \multirow[t]{2}{*}{ Insecure } & & & & $-0.06 * * *$ & & & \\
\hline & & & & $(0.02)$ & & & \\
\hline \multirow[t]{2}{*}{ Violence Civil. } & & & & & $-2.61 * * *$ & & \\
\hline & & & & & $(0.81)$ & & \\
\hline \multirow[t]{2}{*}{ Battles } & & & & & & $-2.92 * * *$ & \\
\hline & & & & & & $(0.72)$ & \\
\hline \multirow[t]{2}{*}{ IDP } & & & & & & & $-0.74 * * *$ \\
\hline & & & & & & & $(0.20)$ \\
\hline Method & Probit & OLS & $2 S L S$ & $2 S L S$ & $2 S L S$ & $2 S L S$ & $2 S L S$ \\
\hline Observations & 2242 & 2252 & 2252 & 2252 & 2252 & 2252 & 2252 \\
\hline Pseudo R-squared & 0.109 & 0.135 & 0.133 & 0.136 & 0.126 & 0.132 & 0.141 \\
\hline 1st stage: Hansen J stat ( $p$-value) & $\mathrm{n} / \mathrm{a}$ & $\mathrm{n} / \mathrm{a}$ & 0.11 & 0.12 & 0.08 & 0.20 & 0.13 \\
\hline 1st stage: $\mathrm{F}$ stat (Kleibergen-Paap) & $\mathrm{n} / \mathrm{a}$ & $\mathrm{n} / \mathrm{a}$ & 26.8 & 25.9 & 19.4 & 28.5 & 26.3 \\
\hline \multicolumn{8}{|c|}{$\begin{array}{l}\text { Note: The unit of observation is an individual. Robust standard errors in parenthesis (adjusted in all Probit regressions for clustering at } \\
\text { district level, and in all OLS and } 2 \text { SLS regressions for two-way clustering at district and ethnicity level). Significance levels } * p<0.1, * * \\
\mathrm{p}<0.05, * * * p<0.01 \text {. All specifications control for unreported individual sociodemographics (Age, Education, Employed, Gender, Rural, Own } \\
\text { TV, Own Radio, } 17 \text { Religion Fixed Effects), districts characteristics at the beginning of the period (Past Generalized Trust, Past Trust in Own } \\
\text { Group, Past Ethnic Identity, Population, Urbanization, Age-Dependency-Ratio, Share of Manufacture, Share of Subsistence Farming, Net } \\
\text { Migration, Number of Micro-Enterprises, Adjusted Total Fertility Rate, Unemployment Rate), county characteristics (Ethnic } \\
\text { Fractionalization), and ethnicity characteristics (Ln of Past Slave Exports per Area). }\end{array}$} \\
\hline
\end{tabular}

Table 4: The Effect of Fighting on Generalized Trust (District Level). 
In an additional robustness check in Table 16 (in Appendix A) we use exclusively district-level information. For this purpose, we exclude individual control variables from the right hand side of equation (1) and collapse all the other variables (both on the right and on the left hand side) at their district average level. The resulting sample consists of only 49 observations (i.e., districts), implying a low number of degrees of freedom. Reassuringly, the results are robust and of a similar magnitude to those in Tables 4 and 15 .

\subsection{Excluding Acholiland}

One might suspect that the previous results are largely driven by Acholiland, the troubled region in the North where most of the fighting between the government and the LRA took place. In fact, this is not the case. In Appendix A, Table 13 we focus on the robustness of the benchmark 2SLS estimates of Generalized trust (Column 3, Table 1) and Ethnic identity (Column 3, Table 3) when the identifying power of Acholiland is mitigated. Columns (1)-(2) refer to the regression for Generalized trust. In column (1) we remove from the sample the counties classified as Acholi by the Geo-Referenced Ethnic Group (GREG) dataset (Weidmann, Rød and Cederman 2010). ${ }^{28}$ In column (2) we remove from the sample the counties classified as Acholi by the Ethnologue (ETHNO) definition of Acholiland (Lewis (ed.) 2009). In neither case are the results significantly different from the benchmark specification of Column 3, Table 1. In columns (3)-(4) we perform the corresponding analysis for Ethnic identity (Table 3 ). The results are again robust.

\subsection{Ethnic group fixed effects}

In the econometric specification (1), ethnic-specific unobserved heterogeneity in trust is partially filtered out by controlling for ethnic-level Slavery and by allowing for ethnic-level clustering of error terms. In this section we refine the procedure by including a full set of ethnic-group fixed effects. This is very demanding from a statistical point of view because Uganda is characterized by a high level of spatial sorting of ethnic groups. As a consequence the identifying power of our geographical instruments (distance to Sudan and maximum elevation) is partially absorbed and mitigated by the fixed effects.

We focus on our preferred dependent variables, namely Generalized trust and Ethnic identity. Tables 5 and 6 are the analogue with ethnic fixed effects of Tables 1 and 3, respectively. Both noninstrumented and instrumented results are robust, albeit quantitatively smaller in absolute value than those in Tables 1 and 3. In some specifications statistical significance is reduced and is close to the $90 \%$ level. As expected, in the instrumented specifications the F-statistics of the first stage regressions (not reported) fall, in some cases, below the conventional threshold of $\mathrm{F}=10$, confirming that the identifying power of the instruments is weakened by the inclusion of the ethnic fixed effects.

\footnotetext{
${ }^{28}$ In particular, this dummy codes as one all counties where Acholis are the largest ethnic group everywhere in the territory according to GREG.
} 


\begin{tabular}{|c|c|c|c|c|c|c|c|}
\hline & \multicolumn{7}{|c|}{ Dependent variable: Generalized Trust in 2008} \\
\hline & $(1)$ & $(2)$ & (3) & (4) & $(5)$ & (6) & (7) \\
\hline \multirow[t]{2}{*}{ All fighting } & $-0.84 *$ & $-0.93^{*}$ & $-3.30 * * *$ & $-3.07 * * *$ & & & \\
\hline & $(0.51)$ & $(0.53)$ & $(1.22)$ & (1.19) & & & \\
\hline \multirow[t]{2}{*}{ Insecure } & & & & $-0.06 * * *$ & & & \\
\hline & & & & $(0.02)$ & & & \\
\hline \multirow[t]{2}{*}{ Violence Civil. } & & & & & $-10.65^{* * *}$ & & \\
\hline & & & & & $(3.67)$ & & \\
\hline \multirow[t]{2}{*}{ Battles } & & & & & & $-4.51 * * *$ & \\
\hline & & & & & & $(1.72)$ & \\
\hline \multirow[t]{2}{*}{ IDP } & & & & & & & $-0.93 * * *$ \\
\hline & & & & & & & $(0.33)$ \\
\hline Method & Probit & OLS & 2SLS & $2 S L S$ & 2SLS & $2 S L S$ & 2SLS \\
\hline Observations & 2234 & 2252 & 2252 & 2252 & 2252 & 2252 & 2252 \\
\hline Pseudo R-squared & 0.146 & 0.181 & 0.170 & 0.175 & 0.157 & 0.175 & 0.185 \\
\hline \multicolumn{8}{|c|}{$\begin{array}{l}\text { Note: The unit of observation is an individual. Robust standard errors in parenthesis (adjusted in all Probit regressions for } \\
\text { clustering at county level, and in all OLS and } 2 \text { SLS regressions for two-way clustering at county and ethnicity level). } \\
\text { Significance levels } * p<0.1, * * p<0.05, * * * p<0.01 \text {. All specifications control for unreported individual sociodemographics } \\
\text { (Age, Education, Employed, Gender, Rural, Own TV, Own Radio, } 17 \text { Religion Fixed Effects), districts characteristics at the } \\
\text { beginning of the period (Past Generalized Trust, Past Trust in Own Group, Past Ethnic Identity, Population, Urbanization, } \\
\text { Age-Dependency-Ratio, Share of Manufacture, Share of Subsistence Farming, Net Migration, Number of Micro-Enterprises, } \\
\text { Adjusted Total Fertility Rate, Unemployment Rate), county characteristics (Ethnic Fractionalization), and Ethnicity Fixed } \\
\text { Effects. }\end{array}$} \\
\hline
\end{tabular}

Table 5: Generalized Trust with Ethnicity Fixed Effects. 


\begin{tabular}{|c|c|c|c|c|c|c|c|}
\hline & \multicolumn{7}{|c|}{ Dependent variable: Ethnic Identity in 2008} \\
\hline & $(1)$ & $(2)$ & (3) & (4) & (5) & (6) & (7) \\
\hline \multirow{2}{*}{ All fighting } & 0.40 & $0.44^{*}$ & $2.22 *$ & $1.98^{*}$ & & & \\
\hline & $(0.26)$ & $(0.24)$ & $(1.23)$ & (1.15) & & & \\
\hline \multirow[t]{2}{*}{ Insecure } & & & & $0.06 * *$ & & & \\
\hline & & & & $(0.03)$ & & & \\
\hline \multirow[t]{2}{*}{ Violence Civil. } & & & & & $7.88^{* *}$ & & \\
\hline & & & & & $(3.47)$ & & \\
\hline \multirow[t]{2}{*}{ Battles } & & & & & & $2.90^{*}$ & \\
\hline & & & & & & $(1.73)$ & \\
\hline \multirow[t]{2}{*}{ IDP } & & & & & & & $0.76^{* * *}$ \\
\hline & & & & & & & $(0.24)$ \\
\hline Method & Probit & OLS & $2 S L S$ & $2 S L S$ & $2 S L S$ & $2 S L S$ & $2 S L S$ \\
\hline Observations & 2217 & 2259 & 2259 & 2259 & 2259 & 2259 & 2259 \\
\hline Pseudo R-squared & 0.086 & 0.093 & 0.085 & 0.091 & 0.073 & 0.089 & 0.088 \\
\hline \multicolumn{8}{|c|}{$\begin{array}{l}\text { Note: The unit of observation is an individual. Robust standard errors in parenthesis (adjusted in all Probit regressions for } \\
\text { clustering at county level, and in all OLS and } 2 \text { SLS regressions for two-way clustering at county and ethnicity level). } \\
\text { Significance levels } * p<0.1, * * p<0.05, * * * p<0.01 \text {. All specifications control for unreported individual sociodemographics } \\
\text { (Age, Education, Employed, Gender, Rural, Own TV, Own Radio, } 17 \text { Religion Fixed Effects), districts characteristics at the } \\
\text { beginning of the period (Past Generalized Trust, Past Trust in Own Group, Past Ethnic Identity, Population, Urbanization, } \\
\text { Age-Dependency-Ratio, Share of Manufacture, Share of Subsistence Farming, Net Migration, Number of Micro-Enterprises, } \\
\text { Adjusted Total Fertility Rate, Unemployment Rate), county characteristics (Ethnic Fractionalization), and Ethnicity Fixed } \\
\text { Effects. }\end{array}$} \\
\hline
\end{tabular}

Table 6: Ethnic Identity with Ethnicity Fixed Effects. 


\subsection{Within-County Ethnic Violence}

The analysis so far has shown that violence across Ugandan counties is associated with a decrease in trust towards other Ugandans and an increase in ethnic identity. In this section, we propose an alternative empirical strategy addressing two related issues. First, we would like to cast more light on the mechanism linking violence to trust. The evidence presented so far could be driven by the effects of inter-ethnic violence on inter-ethnic trust, as well as by the mere exposure of individuals to conflict and violence, irrespective of its causes and of the groups involved. However, some theories, including our earlier work in Rohner, Thoenig and Zilibotti (2011), link the effect of war on social capital to inter-ethnic relationships. According to this view, people's beliefs should respond to violence targeting their own ethnic group rather than to generic violence occurring within their own county. We would like to discriminate between these two channels. Second, the cross-county identification is subject to a caveat. Counties might be subject to unobservable shocks correlated with both a high incidence of conflict and low trust. For example, the government might have reduced during the period under consideration transfers or public goods to districts (or counties) populated by hostile ethnic groups. Unfortunately, we have no direct measure of such policies.

To make progress in this direction, we exploit spatial $\times$ ethnic variations in violence. We use the information provided by ACLED about the nature of each conflict event. Each episode is classified as involving specific rebel groups or ethnic militias, civilians, or the Ugandan army. Many rebel groups have a main ethnic affiliation, e.g. if the ACLED data lists a "battle" between "Bafumbira Ethnic Militia" and "Batooro Ethnic Militia", this would be linked to both the Bafumbira and the Batooro ethnic groups, and, for example, events involving the LRA can be linked to the Acholi group. Therefore, we can associate most events with one or more ethnic groups involved, as well as with the counties where they occurred. ${ }^{29}$ Having constructed such a variable, we identify the effect of violence on trust and ethnic identity out of the within-county variation in the number of events involving different ethnic groups, possibly after controlling for both county and ethnic group fixed effects.

To begin with, column (1) of Table 7 yields the results of the Probit specification of Column (1) in Table 1 after splitting the variable All fighting at the county-level into events involving (i.e. Fight $(\operatorname{Tr}, \mathrm{Cou}))$ and not involving (i.e. Fight $($ OtherTr, Cou $))$ the respondent's ethnic group. The coefficient of Fight(Tr,Cou) (-2.20) is highly significant and twice as large as the coefficient of Fight(OtherTr,Cou), which is statistically insignificant. Column (4) reports the analogue coefficient for the regression in which the dependent variable is Ethnic identity (cf. Table 3). The results are similar - only the coefficient of Fight(Tr,Cou) (0.78) is significantly positive. These regressions show that fighting events linked to a respondent's own ethnic group have a stronger effect on Generalized trust and Ethnic identity than have fighting events involving other ethnic groups.

We consider, next, a very demanding specification including both county and ethnic fixed effect.

\footnotetext{
${ }^{29}$ We have followed a conservative matching strategy, only linking events that can be attributed with a very high confidence to particular groups. The results are similar when a more aggressive matching strategy is used, or when particular rebel groups are removed. The matching table is available from the authors upon publication.
} 


\begin{tabular}{|c|c|c|c|c|c|c|}
\hline Dep. var.: & Gen. Trust & Gen. Trust & Gen. Trust & Identity & Identity & Identity \\
\hline & (1) & $(2)$ & (3) & (4) & (5) & (6) \\
\hline \multirow[t]{2}{*}{ Fight(OtherTr,Cou) } & -1.09 & & & 0.28 & & \\
\hline & $(0.71)$ & & & $(0.51)$ & & \\
\hline \multirow[t]{2}{*}{ Fight(Tr,Cou) } & $-2.20 * * *$ & & & $0.78 * *$ & & \\
\hline & $(0.64)$ & & & $(0.37)$ & & \\
\hline \multirow[t]{2}{*}{ Fight(Tr)*Fight(Cou) } & & -0.31 & -0.40 & & $1.83^{* *}$ & $1.87 * *$ \\
\hline & & $(0.67)$ & (0.69) & & $(0.89)$ & $(0.81)$ \\
\hline \multirow[t]{2}{*}{ Fight(Tr)*Radio } & & & $-0.08 * *$ & & & $0.07 * *$ \\
\hline & & & $(0.03)$ & & & $(0.03)$ \\
\hline Method & Probit & Probit & Probit & Probit & Probit & Probit \\
\hline Fixed Effects & No & County, Tribe & County, Tribe & No & County, Tribe & County, Tribe \\
\hline Observations & 2242 & 2341 & 2341 & 2256 & 2280 & 2280 \\
\hline R-squared & 0.102 & 0.204 & 0.205 & 0.057 & 0.118 & 0.12 \\
\hline
\end{tabular}

Note: The unit of observation is an individual. Standard errors in parenthesis (robust, clustered at county level). Significance levels $* p<0.1, * * p<0.05, * * * p<0.01$. All specifications control for unreported individual sociodemographics (Age, Education, Employed, Gender, Rural, Own TV, Own Radio, 17 Religion Fixed Effects), and columns (1) and (4) for districts characteristics at the beginning of the period (Past Generalized Trust, Past Trust in Own Group, Past Ethnic Identity, Population, Urbanization, Age-Dependency-Ratio, Share of Manufacture, Share of Subsistence Farming, Net Migration, Number of Micro-Enterprises, Adjusted Total Fertility Rate, Unemployment Rate), county characteristics (Ethnic Fractionalization), and ethnicity characteristics (Ln of Past Slave Exports per Area).

Table 7: Ethnic Fighting, Generalized Trust and Identity. 
In this specification, the main effects of fighting are absorbed by the fixed effects and the variable of interest becomes Fight( $\mathrm{Tr})^{*}$ Fight(Cou), which is an interaction term of all fighting events occurring in the county of which the respondent is resident times all fighting events throughout Uganda involving the ethnic group of the respondent. All spatial controls are now absorbed by the county fixed effects. The main results are presented in columns (2) for Generalized trust and (5) for Ethnic identity. The point estimates of the interaction effects are, as expected, negative (-0.31) and positive (1.83), respectively, although only the coefficient in the regression for Ethnic identity is statistically significant (at the $5 \%$ level).

So far, besides the last specification of columns (2) and (5), we have throughout the paper focused on the effects of violence which occurred in the respondent's county. This is a plausible assumption, since our All fighting variable codes even minor episodes whose knowledge is unlikely to be shared across all Ugandans. However, well-informed individuals may be affected by the exposure to the news of ethnic violence involving their group anywhere in Uganda. In columns (3) and (6), we include Fight $(T r)^{*}$ Radio, an interaction between the ownership of a radio and the number of fighting events at the Ugandan national level involving the respondent's group. As expected the interaction coefficient is negative and significant in the case of Generalized trust, and positive and significant in the case of Ethnic identity. People owning a radio are more responsive to the news of violence involving their own ethnic group anywhere in Uganda. ${ }^{30}$

In conclusion, this section shows that the ethnic channel plays an important role. In (unreported) regressions, we show that results are also robust to controlling for the self-reported measure of individual exposure to violence, Insecurity. This implies that the results of this Section do not appear to be driven by the personal threat suffered by members of specific groups. Moreover, the within-county results rule out that the increase in ethnic identity is driven by targeted government policies, e.g., the government spending less on hostile districts or counties. A caveat is that we cannot instrument the within-county variation in events involving different ethnic groups. Yet, we believe that the different econometric subsections discussed in this section provide jointly robust evidence of a causal effect of ethnic conflict on different dimensions of social capital.

\section{The Heterogenous Effects of Conflict on Economic Activity}

In this section we study the effect of violence on economic outcomes and living standards. Ideally, we would like to use county-level GDP as the dependent variable, but this is not available in Uganda. We use two alternative proxies. First, we use information from the responses to the Afrobarometer 2008

\footnotetext{
${ }^{30}$ We interpret this result as an interesting correlation. There is a growing literature studying politico-economic effects of mass media (see Strömberg 2004 for a seminal contribution). Recent applications to ethnic conflict include Della Vigna et al. (2011), and Yanagizawa (2010), focusing respectively on partisan radio broadcasting in the Serbo-Croatian and Rwandan conflicts. These papers show that an exogenous increase in the exposure to radical news affects people's attitude about ongoing conflicts. In this paper, we do not try to identify exogenous variation in the exposure to radio broadcasting. Thus, the effect identified by our regression could reflect some self-selection of individuals in the decision of owning a radio.
} 
question about individual living condition. Living condition is set equal to one whenever the survey respondent declares his living conditions to be either good or very good, and is set to zero when the respondent declares them to be either bad or very bad. The main problem with this variable is that it may reflect subjective assessments potentially affected by non-economic components of well-being. Second, we use Satellite Nightlight Data from the National Oceanic and Atmospheric Administration (2010). The raw data is produced by meteorologic satellites that measure light intensity during night. These data have been used in recent research as a proxy for economic activity (cf. for example Henderson, Storeygard, and Weil 2011, and Hodler and Raschky 2011). The exact data construction is detailed in the Data Appendix.

The focal point of our analysis is the extent to which post-conflict recovery is heterogeneous across counties characterized by different ethnic fractionalization. In particular, our hypothesis is that if conflict destroys inter-ethnic trust, more fractionalized counties that depend more heavily on interethnic business would suffer stronger and more persistent economic effects.

When the dependent variable is Living condition, we estimate the following equation:

$$
\begin{aligned}
L I V I N G_{-} C O N D_{i, c, e}^{08}= & \Phi\left[\alpha_{0}+\alpha_{1} L I V I N G_{-} C O N D_{d}^{00}+\alpha_{2} F_{I G H T I N G}^{00-08}+\alpha_{3} F R A C_{c}(2)\right. \\
& \left.+\alpha_{4} \text { FIGHTING }_{c}^{00-08} \times F R A C_{c}+\alpha_{5} \text { Slavery }_{d}+\mathbf{X}_{i}^{\prime} \boldsymbol{\beta}+\mathbf{Z}_{d}^{\prime} \gamma+u_{i, c, e}\right] .
\end{aligned}
$$

In the case of Satellite light, the dependent variable is measured at the county level and we ignore all individual information. We consequently estimate the following equation:

$$
\begin{aligned}
\text { SATELL_LIGHT } & 08= \\
& \Phi\left[\alpha_{0}+\alpha_{1} S A T E L L_{-} L I G H T_{c}^{00}+\alpha_{2} F I G H T I N G_{c}^{00-08}+\alpha_{3} F R A C(3)\right. \\
& \left.+\alpha_{4} F I G H T I N G_{c}^{00-08} \times F R A C_{c}+u_{c}\right] .
\end{aligned}
$$

We use a Tobit regressor since satellite light data are censored at zero. In both specifications, the main coefficient of interest is $\alpha_{4}$.

The results are reported in Tables 8-9. Column (1) in both tables shows that All fighting has a negative (but statistically not robust) effect in 2008 once initial conditions in 2000 are controlled for. Column (2) in Table 8 shows that there is a negative and significant interaction effect: Fighting affects Living condition negatively in highly ethnically fractionalized counties. Since the main effects are measured at a zero level of fractionalization, the insignificant coefficient on All fighting indicates that violence has no economic effect in non-fractionalized counties. The result is robust to using OLS instead of Probit (column (3)). A similar result is found in the Tobit regression of Table 9 with Satellite light as the dependent variable.

As usual, it is difficult to instrument the interaction term. To make progress in this direction, we follow Besley and Persson (2011) and split the sample into high- and low-fractionalization counties, instrumenting in each specification All fighting with the same geographic characteristics as previously. Since $47 \%$ of the counties have zero fractionalization, and $75 \%$ have a measure of fractionalization 


\begin{tabular}{|c|c|c|c|c|c|c|c|c|}
\hline \multicolumn{9}{|c|}{ Dependent variable: Living Conditions in 2008} \\
\hline Model: & (1) & $(2)$ & (3) & (4) & (5) & (6) & (7) & (8) \\
\hline \multirow[t]{2}{*}{ Liv. cond. 2000} & $0.22 *$ & $0.22 *$ & $0.22 *$ & 0.01 & $1.29 * * *$ & 0.14 & $0.25 * *$ & 0.07 \\
\hline & $(0.13)$ & $(0.13)$ & $(0.12)$ & $(0.28)$ & $(0.24)$ & $(0.13)$ & $(0.13)$ & $(0.15)$ \\
\hline \multirow[t]{2}{*}{ All fighting } & $-0.82^{*}$ & $-0.69 *$ & $-0.68 * *$ & -1.89 & 2.69 & & & \\
\hline & $(0.43)$ & $(0.40)$ & $(0.33)$ & $(1.29)$ & $(8.16)$ & & & \\
\hline \multirow[t]{2}{*}{ Ethnic frac. } & 0.01 & 0.03 & 0.04 & -0.04 & -0.16 & 0.03 & 0.03 & 0.02 \\
\hline & $(0.09)$ & $(0.09)$ & $(0.10)$ & $(0.26)$ & $(0.21)$ & $(0.09)$ & $(0.09)$ & $(0.09)$ \\
\hline \multirow[t]{2}{*}{ Fighting*Frac } & & -5.04 & $-4.82^{* *}$ & & & & & \\
\hline & & (3.49) & (1.93) & & & & & \\
\hline \multirow[t]{2}{*}{ Civ. viol. } & & & & & & $-3.02 * *$ & & \\
\hline & & & & & & $(1.29)$ & & \\
\hline \multirow[t]{2}{*}{ Civ. ${ }^{*}$ Frac } & & & & & & $-16.28 * *$ & & \\
\hline & & & & & & (8.11) & & \\
\hline \multirow[t]{2}{*}{ Battles } & & & & & & & -0.71 & \\
\hline & & & & & & & $(0.56)$ & \\
\hline \multirow[t]{2}{*}{ Battles*Frac } & & & & & & & -6.15 & \\
\hline & & & & & & & $(4.47)$ & \\
\hline \multirow[t]{2}{*}{ IDP } & & & & & & & & $-0.28 * * *$ \\
\hline & & & & & & & & $(0.10)$ \\
\hline \multirow[t]{2}{*}{ IDP*Frac } & & & & & & & & $-0.72 *$ \\
\hline & & & & & & & & $(0.39)$ \\
\hline Method & Probit & Probit & OLS & $2 S L S$ & $2 S L S$ & Probit & Probit & Probit \\
\hline Sample & All & All & All & Low Frac. & High Frac. & All & All & All \\
\hline Observations & 2236 & 2236 & 2241 & 1687 & 554 & 2236 & 2236 & 2236 \\
\hline R-squared & 0.059 & 0.059 & 0.081 & 0.080 & 0.200 & 0.063 & 0.058 & 0.065 \\
\hline
\end{tabular}

Note: The unit of observation is an individual. Robust standard errors in parenthesis (adjusted in all Probit regressions for clustering at county level, and in all OLS and 2SLS regressions for two-way clustering at county and ethnicity level). Significance levels ${ }^{*} p<0.1,{ }^{*}$ $p<0.05, * * * p<0.01$. All specifications control for unreported individual sociodemographics (Age, Education, Employed, Gender, Rural, Own TV, Own Radio, 17 Religion Fixed Effects), districts characteristics at the beginning of the period (Past Generalized Trust, Past Trust in Own Group, Past Ethnic Identity, Population, Urbanization, Age-Dependency-Ratio, Share of Manufacture, Share of Subsistence Farming, Net Migration, Number of Micro-Enterprises, Adjusted Total Fertility Rate, Unemployment Rate), county characteristics (Ethnic Fractionalization), and ethnicity characteristics (Ln of Past Slave Exports per Area).

Table 8: Explaining Living Conditions in 2008. 
below $23 \%$, we set the threshold at the top quartile. Thus, the sample of low-fractionalization (highfractionalization) counties consists of the three lowest quartiles (respectively, top quartile). The coefficient of interest are now the main effects of All fighting, separately for low- and high-fractionalizaton counties, in columns (4)-(5) of Table 8 and in columns (3)-(4) of Table 9, respectively. In the case of the Living condition (Table 8), we find no significant difference: all estimated coefficients are small and imprecisely estimated. In contrast, in the case of Satellite light (Table 9), fighting is associated with a large and significant fall in living conditions in high-fractionalization counties (column (4)), and with no significant effect in less fractionalized counties (column (3)). ${ }^{31}$ The coefficient of All fighting in high-fractionalization counties is seven times larger. In the last three columns of the tables 8 and 9 we show that the results are similar for alternative measures of fighting.

The finding that ethnic violence dating back to 2002-05 has a negative effect on economic outcomes measured in 2008 in ethnically fractionalized counties is consistent with the view that conflict hinders economic cooperation in ethnically divided societies. The evidence suggests that the effects of violence on social capital has weaker effects on economic cooperation when violence does not involve ethnic cleavages. In other words, violence appears to have more persistent effects in ethnically divided areas.

\section{Conclusions}

We have studied the effect of civil conflict on social capital, focusing on the experience of Uganda during the last decade. Using individual and county-level data, we document causal effects of an outburst of civil conflict in 2002-05, driven by an exogenous shock linked to US foreign policy, on post-conflict trust and ethnic identity. We find that the extent of fighting has a strong and statistically significant negative impact on Trust towards other Ugandans between 2000 and 2008. The estimated effect is quantitatively large and robust to a number of control variables, alternative measures of violence and different statistical techniques. The effects on Trust in relatives is insignificant. On the contrary, people living in districts experiencing more violence report a strong increase in a measure of Ethnic identity, i.e., they identify themselves more strongly with their own ethnic group relative to alternative forms of national affiliation. Thus, conflict appears to strengthen within-ethnic group solidarity. This finding is consistent with the casual evidence that social capital is fueled by external wars: countries acquire a stronger internal cohesion.

The results are robust to various specifications including instrumental variable strategy. In addition, the findings are robust to a demanding identification strategy relying on the variation within each district in the ethnic violence involving different ethnic groups. The importance of ethnic elements suggests that the destruction of social capital may not be a psychological response only due to the mere exposure of individuals to violence. Nor do the findings appear to be driven by fear or insecurity at the individual level, since these are controlled for in some of our regressions.

\footnotetext{
${ }^{31}$ The small sample size in the split sample reduces the power of the first-stage regression. The Kleibergen-Paap F-stats are well below ten, raising a concern with a weak-instrument bias.
} 


\begin{tabular}{|c|c|c|c|c|c|c|c|}
\hline \multicolumn{8}{|c|}{ Dependent variable: Satellite light in 2008} \\
\hline Model: & (1) & $(2)$ & (3) & (4) & (5) & (6) & (7) \\
\hline \multirow[t]{2}{*}{ Sat.light (2000) } & $0.83 * * *$ & $0.84 * * *$ & $0.81 * * *$ & $0.93 * * *$ & $0.84 * * *$ & $0.84^{* * *}$ & $0.82^{* * *}$ \\
\hline & $(0.09)$ & $(0.09)$ & $(0.11)$ & $(0.08)$ & $(0.09)$ & $(0.09)$ & $(0.09)$ \\
\hline \multirow[t]{2}{*}{ All fighting } & -0.72 & -0.44 & -1.86 & $-13.22 * *$ & & & \\
\hline & $(1.32)$ & $(1.32)$ & $(1.98)$ & $(5.50)$ & & & \\
\hline \multirow[t]{2}{*}{ Ethnic frac. } & 0.04 & 0.15 & 2.92 & 0.29 & 0.14 & 0.12 & 0.11 \\
\hline & $(0.13)$ & $(0.13)$ & $(2.00)$ & $(0.25)$ & $(0.13)$ & $(0.13)$ & $(0.13)$ \\
\hline \multirow[t]{2}{*}{ Fighting*Frac } & & $-29.83 * *$ & & & & & \\
\hline & & $(13.67)$ & & & & & \\
\hline \multirow[t]{2}{*}{ Civ. viol. } & & & & & -0.54 & & \\
\hline & & & & & $(3.05)$ & & \\
\hline \multirow[t]{2}{*}{ Civ. ${ }^{*}$ Frac } & & & & & $-68.43^{* *}$ & & \\
\hline & & & & & $(30.26)$ & & \\
\hline \multirow[t]{2}{*}{ Battles } & & & & & & -0.54 & \\
\hline & & & & & & $(2.06)$ & \\
\hline \multirow[t]{2}{*}{ Battles*Frac } & & & & & & -47.26 & \\
\hline & & & & & & $(27.12)$ & \\
\hline \multirow[t]{2}{*}{ IDP } & & & & & & & -0.10 \\
\hline & & & & & & & $(0.15)$ \\
\hline \multirow[t]{2}{*}{ IDP*Frac } & & & & & & & $-10.40 * * *$ \\
\hline & & & & & & & $(3.97)$ \\
\hline Method & Tobit & Tobit & IVTobit & IVTobit & Tobit & Tobit & Tobit \\
\hline Sample & All & All & Low Frac. & High Frac. & All & All & All \\
\hline Observations & 125 & 125 & 75 & 43 & 125 & 125 & 125 \\
\hline Log Pseudolikelihood & -21.64 & -19.18 & 152.23 & 154.31 & -19.02 & -19.82 & -18.18 \\
\hline \multicolumn{8}{|c|}{$\begin{array}{l}\text { Note: The unit of observation is a county. Robust standard errors in parenthesis. Significance levels } * p<0.1, * * p<0.05, * * * \\
\mathrm{p}<0.01 \text {. All specifications control for districts characteristics at the beginning of the period (Past Generalized Trust, Past Trust in } \\
\text { Own Group, Past Ethnic Identity, Population, Urbanization, Age-Dependency-Ratio, Share of Manufacture, Share of Subsistence } \\
\text { Farming, Net Migration, Number of Micro-Enterprises, Adjusted Total Fertility Rate, Unemployment Rate) and county } \\
\text { characteristics (Ethnic Fractionalization). }\end{array}$} \\
\hline
\end{tabular}

Table 9: Explaining Living Conditions in 2008 (Measured Using Satellite Light Data). 
We also study post-conflict economic recovery. Few years after the conflict outburst, the intensity of fighting has a negative effect on the economic situation in highly fractionalized counties, but no effect in less fractionalized counties. We interpret this finding as consistent with recent theories emphasizing the negative effect of ethnic conflict on inter-ethnic economic cooperation and business links that we studied from a theoretical perspective in a recent companion paper (Rohner, Thoenig and Zilibotti 2011). Our empirical results suggest the existence of such a self-reinforcing process between conflicts and ethnic cleavages.

We plan to extend the approach in this paper to the study of civil conflicts in other African countries.

\section{References}

[1] Acemoglu, Daron, and Alexander Wolitzky, 2012, "Cycles of Distrust: An Economic Model", mimeo, Massachusetts Institute of Technology.

[2] ACLED, 2011, "Armed Conflict Location and Event Data", dataset, www.acleddata.com.

[3] Afrobarometer, 2000, "Round 1 Afrobarometer Survey in Uganda", dataset, www.afrobarometer.org.

[4] Afrobarometer, 2008, "Round 4 Afrobarometer Survey in Uganda", dataset, www.afrobarometer.org.

[5] Afrobarometer, 2011, "Surveys and Methods", www.afrobarometer.org.

[6] Akresh, Richard, and Damien de Walque, 2010, "Armed Conflict and Schooling: Evidence from the 1994 Rwandan Genocide", mimeo, University of Illinois at Urbana-Champaign and World Bank.

[7] Alesina, Alberto, and Eliana La Ferrara, 2000, "Participation in Heterogeneous Communities", Quarterly Journal of Economics 115: 847-904.

[8] Alesina, Alberto, and Eliana La Ferrara, 2002, "Who trusts others?", Journal of Public Economics 85: 207-234.

[9] Alesina, Alberto, and Ekaterina Zhuravskaya, 2011, "Segregation and the Quality of Government in a Cross-Section of Countries", forthcoming in American Economic Review.

[10] Algan, Yann, and Pierre Cahuc, 2010, "Inherited Trust and Growth", American Economic Review 100: 2060-2092.

[11] Altonji, Joseph, Todd Elder, and Christopher Taber, 2005, "Selection on Observed and Unobserved Variables: Assessing the Effectiveness of Catholic Schools", Journal of Political Economy 113: 151-184. 
[12] Angrist Joshua, and Jörn-Steffen Pischke, 2009. Mostly harmless econometrics: an empiricist's companion, Princeton NJ: Princeton University Press.

[13] Balcells, Laia, 2011, "The Consequences of Victimization on Political Identities: Evidence from Spain", forthcoming in Politics and Society.

[14] Barenbaum, Joshua, Vladislav Ruchkin, and Mary Schwab-Stone, 2004, "The psychological aspects of children exposed to war: practice and policy initiatives", Journal of Child Psychology and Psychiatry 45: 41-62.

[15] Bellows, John, and Edward Miguel, 2009, "War and local collective action in Sierra Leone", Journal of Public Economics 93: 1144-57.

[16] Besley, Timothy, and Torsten Persson, 2011, "The Logic of Political Violence", forthcoming in Quarterly Journal of Economics.

[17] Besley, Timothy, and Marta Reynal-Querol, 2012, "The Legacy of Historical Conflict: Evidence from Africa", mimeo, London School of Economics.

[18] Blattman, Christopher, 2009, "From Violence to Voting: War and Political Participation in Uganda", American Political Science Review 103: 231-47.

[19] Blattman, Christopher, and Jeannie Annan, 2009, "The Consequences of Child Soldiering", forthcoming in Review of Economics and Statistics.

[20] Bowles, Samuel, and Herbert Gintis, 2004, "Persistent parochialism: trust and exclusion in ethnic networks", Journal of Economic Behavior and Organization 55: 1-23.

[21] Bozzoli, Carlos, Tilman Brueck, and Tony Muhumuza, 2011, "Does war influence individual expectations?", forthcoming in Economic Letters.

[22] Bun, Maurice and Monique de Haan, 2010, "Weak instruments and the first stage F-statistic in IV models with a nonscalar error covariance structure", Discussion Paper 2010/02, University of Amsterdam.

[23] Caselli, Francesco, and Wilbur John Coleman II, 2011, "On the Theory of Ethnic Conflict", mimeo, LSE and Duke University.

[24] Cassar, Alessandra, Pauline Grosjean, and Sam Whitt, 2011, "Lost in Transition? How Civil War Violence Can Impair the Foundations for Market Development", mimeo UC San Francisco, University of New South Wales and U.S. State Department.

[25] Choi, Jung-Kyoo, and Samuel Bowles, 2007, "The Coevolution of Parochial Altruism and War", Science 318: 636-640. 
[26] Collier, Paul, 1999, "On the economic consequences of civil war", Oxford Economic Papers 51: 168-83.

[27] Collier, Paul and Anke Hoeffler, 2004, "Greed and grievance in civil war", Oxford Economic Papers 56: 563-95.

[28] Collier, Paul, Anke Hoeffler, and Dominic Rohner, 2009, "Beyond Greed and Grievance: Feasibility and Civil War", Oxford Economic Papers 61: 1-27.

[29] Collier, Paul, and Dominic Rohner, 2008, "Democracy, Development, and Conflict", Journal of the European Economic Association 6: 531-40.

[30] Dasgupta, Partha, 1988, "Trust as a Commodity" in Diego Gambetta (ed.), Trust: Making and Breaking Cooperative Relations, Oxford, Basil Blackwell.

[31] Dasgupta, Partha, 1999, "Economic Progress and the Idea of Social Capital" in Partha Dasgupta and Ismail Serageldin (eds.), Social Capital: A Multifaceted Perspective, Washington, World Bank.

[32] Deininger, Klaus, 2003, "Causes and consequences of civil strife: micro-level evidence from Uganda", Oxford Economic Papers 55: 579-606.

[33] DellaVigna, Stefano, Ruben Enikolopov, Vera Mironova, Maria Petrova and Ekaterina Zhuravskaya, 2011, "Unintended media effects in a conflict environment: Serbian radio and Croatian nationalism", NBER Working Paper No. 16989.

[34] De Luca, Giacomo, and Marijke Verpoorten, 2011, "From vice to virtue? Civil war and social capital in Uganda", HiCN Working Paper 111, Katholieke Universiteit Leuven, December 2011.

[35] Derluyn, Ilse, Eric Broekaert, Gilberte Schuyten, and Els De Temmerman, 2004, "Post-traumatic stress in former Ugandan child soldiers", Lancet 363: 861-3.

[36] DeRouen, Karl, and Jacob Bercovitch, 2008, "Enduring Internal Rivalries: A New Framework for the Study of Civil War", Journal of Peace Research 45: 55-74.

[37] Dolan, Chris, 2009, Social Torture: The Case of Northern Uganda, 1986-2006, New York: Berghahn Books.

[38] Dyregrov, Atle, Leila Gupta, Rolf Gjestad, and Eugenie Mukanoheli, 2000, "Trauma Exposure and Psychological Reactions to Genocide Among Rwandan Children", Journal of Traumatic Stress 13: 3-21.

[39] Dyregrov, Atle, Rolf Gjestad, and Magne Raundalen, 2002, "Children Exposed to Warfare: A Longitudinal Study", Journal of Traumatic Stress 15: 59-68. 
[40] Eichengreen, Barry, 2008, The European Economy since 1945: Coordinated Capitalism and Beyond, Princeton NJ: Princeton University Press.

[41] Esteban, Joan, Laura Mayoral, and Debraj Ray, 2011, "Ethnicity and Conflict: An Empirical Study", mimeo, IAE and NYU.

[42] Esteban, Joan, Massimo Morelli, and Dominic Rohner, 2011, "Strategic Mass Killings", mimeo, IAE, Columbia University and University of Zurich.

[43] Esteban, Joan, and Debraj Ray, 2008, "On the Salience of Ethnic Conflict", American Economic Review 98: 2185-202.

[44] Esteban, Joan, and Debraj Ray, 2011, "Linking Conflict to Inequality and Polarization", forthcoming in American Economic Review.

[45] Fafchamps, Marcel, 2000, "Ethnicity and credit in African manufacturing", Journal of Development Economics 61: 205-35.

[46] Fearon, James, Macartan Humphreys, and Jeremy Weinstein, 2009, "Can Development Aid Contribute to Social Cohesion after Civil War? Evidence from a Field Experiment in PostConflict Liberia", American Economic Review 99: 287-291.

[47] Fearon, James, and David Laitin, 2003, "Ethnicity, Insurgency, and Civil War", American Political Science Review 97: 75-90.

[48] Fehr, Ernst, 2009, "On the Economics and Biology of Trust", Journal of the European Economic Association 7: 235-266.

[49] Finnström, Sverker, 2008, Living with Bad Surroundings: War, History, and Everyday Moments in Northern Uganda, Durham: Duke University Press.

[50] Fisman, Raymond, 2003, "Ethnic Ties and the Provision of Credit: Relationship-Level Evidence from African Firms", Advances in Economic Analysis 8 Policy 3: Article 4.

[51] Fryer, Roland, and Steven Levitt, 2004, "The Causes and Consequences of Distinctively Black Names", Quarterly Journal of Economics 119: 767-805.

[52] Gilligan, Michael, Benjamin Pasquale and Cyrus Samii, 2010, "Civil War and Social Capital: Behavioral-Game Evidence from Nepal", mimeo, NYU and Columbia University.

[53] Giuliano, Paola, and Antonio Spilimbergo, 2009, "Growing Up in a Recession: Beliefs and the Macroeconomy", NBER Working Paper 15321.

[54] Guiso, Luigi, Paola Sapienza, and Luigi Zingales, 2006, "Does Culture Affect Economic Outcomes?", Journal of Economic Perspectives 20: 23-48. 
[55] Guiso, Luigi, Paola Sapienza, and Luigi Zingales, 2009, "Cultural biases and economic exchange", Quarterly Journal of Economics 124: 1095-1131.

[56] Gurr, Ted, 1993, Minorities at risk: A global view of ethnopolitical conflicts, Washington DC: United States Institute of Peace Press.

[57] Henderson, Vernon, Adam Storeygard, and David Weil, 2011, "Measuring Economic Growth from Outer Space", forthcoming in American Economic Review.

[58] Hijmans Lab at UCDavis, 2010, "Elevation data", dataset, http://biogeo.ucdavis.edu/data/diva/msk_alt/UGA_msk_alt.zip.

[59] Hodler, Roland, and Paul Raschky, 2011, "Foreign Aid and Enlightened Leaders", mimeo, Study Center Gerzensee and Monash University.

[60] Horowitz, Donald, 2000, Ethnic Groups in Conflict, Berkeley: University of California Press (2nd edition).

[61] Humphreys, Macartan, and Jeremy Weinstein, 2007, "Demobilization and Reintegration", Journal of Conflict Resolution 51: 531-67.

[62] Jha, Saumitra, 2008, "Trade, institutions and religious tolerance: evidence from India", mimeo, Stanford University.

[63] Kohrt, Brandon, Mark Jordans, Wietse Tol, Rebecca Speckman, Sujen Maharjan, Carol Worthman, and Ivan Komproe, 2008, "Comparison of Mental Health Between Former Child Soldiers and Children Never Conscripted by Army Groups in Nepal", Journal of the American Medical Association 300: 691-702.

[64] Leon, Gianmarco, 2009, "Civil Conflict and Human Capital Accumulation: The Long Term Effects of Political Violence in Peru", BREAD Working Paper 245.

[65] Lewis, M. Paul (ed.), 2009, Ethnologue: Languages of the World, Sixteenth edition, Dallas: SIL International. Online version for "Languages of Uganda": http://www.ethnologue.com/show_country.asp?name=UG.

[66] Macours, Karen, 2004, "Ethnic Divisions, Contract Choice and Search Costs in the Guatemalan Land Rental Market", mimeo, Johns Hopkins University.

[67] Médecins sans frontières, 2004, Life in Northern Uganda: All Shades of Grief and Fear, report.

[68] Miguel, Edward, Sebastian Saiegh, and Shanker Satyanath, 2011, "Civil war exposure and violence", Economics and Politics 23: 59-73. 
[69] Montalvo, José, and Marta Reynal-Querol, 2005, "Ethnic Polarization, Potential Conflict, and Civil Wars", American Economic Review 95: 796-816.

[70] Nannyonjo, Justine, 2005, "Conflicts, Poverty and Human Development in Northern Uganda", The Round Table 94: 473-488.

[71] National Oceanic and Atmospheric Administration, 2010, "Version 4 DMSP-OLS Nighttime Lights Time Series", dataset, http://www.ngdc.noaa.gov/dmsp/downloadV4composites.html\#AXP.

[72] Neu, Joice 2002 "Restoring relations between Uganda and Sudan: The Carter Center process" Conciliation Resources, http://www.c-r.org/our-work/accord/northern-uganda/cartercenter.php.

[73] Nunn, Nathan, and Leonard Wantchekon, 2011, "The Slave Trade and the Origins of Mistrust in Africa", forthcoming in American Economic Review.

[74] Posner, Daniel, 2004, "The Political Salience of Cultural Difference: Why Chewas and Tumbukas Are Allies in Zambia and Adversaries in Malawi", American Political Science Review 98: 529545.

[75] Putnam, Robert, Robert Leonardi, and Rafaella Nanetti, 1993, Making democracy work: Civic traditions in modern Italy, Princeton NJ: Princeton University Press.

[76] Quinn, J. Michael, David Mason and Mehmet Gurses, 2007, "Sustaining the Peace: Determinants of Civil War Recurrence", International Interactions 33: 167-193.

[77] Rohner, Dominic, 2011, "Reputation, Group Structure and Social Tensions", Journal of Development Economics 96: 188-199.

[78] Rohner, Dominic, Mathias Thoenig, and Fabrizio Zilibotti, 2011, "War Signals: A Theory of Trade, Trust and Conflict", mimeo, University of Zurich and University of Lausanne.

[79] Shemyakina, Olga, 2010, "The effect of armed conflict on accumulation of schooling: Results from Tajikistan", forthcoming in Journal of Development Economics.

[80] Sobel, Joel, 2002, "Can We Trust Social Capital?", Journal of Economic Literature XL: 139-154.

[81] Strömberg, David, 2004, "Radio's impact on public spending", Quarterly Journal of Economics 119: 189-221.

[82] Swee, Eik Leong, 2008, "On War and Schooling Attainment: The Case of Bosnia and Herzegovina", mimeo, University of Toronto. 
[83] Tilly, Charles, 1975, The Formation of National States in Western Europe, Princeton NJ: Princeton University Press.

[84] Ugandan Bureau of Statistics, 2002, "Census 2002", dataset, http://www.ubos.org.

[85] UN, 2009, United Nations' Peace Building and Recovery Assistance Programme For Northern Uganda 2009-2011 (UNPRAP), report.

[86] UNHCR, 2006, Annual Statistic Report on Uganda, dataset, direct correspondence.

[87] UNHCR, 2010, Statistical Online Population Database, dataset, www.unhcr.org.

[88] UNOCHA, 2002, Pushing the envelope: Moving Beyond 'Protected Villages' in Northern Uganda, report.

[89] Vargas Hill, Ruth, Tanguy Bernard, and Reno Dewina, 2008, "Cooperative behaviour in rural Uganda: Evidence from the Uganda National Household Survey 2005", International Food Policy Research Institute Background Paper.

[90] Varshney, Ashutosh, 2003, Ethnic Conflict and Civic Life: Hindus and Muslims in India, New Haven: Yale University Press.

[91] Voors, Maarten, Eleonora Nillesen, Philip Verwimp, Erwin Bulte, Robert Lensink and Daan van Soest, 2010, "Does Conflict affect Preferences? Results from Field Experiments in Burundi", forthcoming in American Economic Review.

[92] Walter, Barbara, 2004, "Does Conflict Beget Conflict? Explaining Recurring Civil War", Journal of Peace Research 41: 371-88.

[93] Weidmann, Nils B., Jan Ketil Rød and Lars-Erik Cederman, 2010, "Representing Ethnic Groups in Space: A New Dataset", Journal of Peace Research 47: 491-499.

[94] Whitt, Sam, and Rick Wilson, 2007, "The Dictator Game, Fairness and Ethnicity in Postwar Bosnia", American Journal of Political Science 51: 655-68.

[95] Women's Commission, 2001, "Against All Odds: Surviving the War on Adolescents", research study, http://www.womenscommission.org/.

[96] World Values Survey, 2009, World Values Survey, dataset http://www.worldvaluessurvey.org/index_html.

[97] Yanagizawa-Drott, David, 2010, "Propaganda and Conflict: Theory and Evidence from the Rwandan Genocide", mimeo, Harvard University. 


\section{Appendix A (not for publication): Additional Tables}

In this Appendix we provide a number of additional tables that are referred to in the text.

\begin{tabular}{|c|c|c|c|c|c|c|c|}
\hline & \multicolumn{7}{|c|}{ Dependent variable: Trust in Known People in 2008} \\
\hline & $(1)$ & $(2)$ & (3) & (4) & (5) & (6) & (7) \\
\hline \multirow[t]{2}{*}{ All fighting } & $-1.79 * * *$ & $-1.80 * * *$ & $-3.54 * * *$ & $-3.19 * * *$ & & & \\
\hline & $(0.44)$ & $(0.65)$ & $(1.14)$ & $(1.16)$ & & & \\
\hline \multirow[t]{2}{*}{ Insecure } & & & & $-0.08 * *$ & & & \\
\hline & & & & $(0.03)$ & & & \\
\hline \multirow[t]{2}{*}{ Violence Civil. } & & & & & $-7.80 * *$ & & \\
\hline & & & & & $(3.06)$ & & \\
\hline \multirow[t]{2}{*}{ Battles } & & & & & & $-5.74 * * *$ & \\
\hline & & & & & & $(1.74)$ & \\
\hline \multirow[t]{2}{*}{ IDP } & & & & & & & $-0.42 * *$ \\
\hline & & & & & & & $(0.17)$ \\
\hline Method & Probit & OLS & $2 S L S$ & 2SLS & $2 S L S$ & $2 S L S$ & $2 S L S$ \\
\hline Observations & 2240 & 2250 & 2250 & 2250 & 2250 & 2250 & 2250 \\
\hline Pseudo R-squared & 0.066 & 0.091 & 0.082 & 0.090 & 0.080 & 0.083 & 0.098 \\
\hline
\end{tabular}

Note: The unit of observation is an individual. Robust standard errors in parenthesis (adjusted in all Probit regressions for clustering at county level, and in all OLS and 2SLS regressions for two-way clustering at county and ethnicity level). Significance levels $* p<0.1, * * p<0.05, * * * p<0.01$. All specifications control for unreported individual sociodemographics (Age, Education, Employed, Gender, Rural, Own TV, Own Radio, 17 Religion Fixed Effects), districts characteristics at the beginning of the period (Past Generalized Trust, Past Trust in Own Group, Past Ethnic Identity, Population, Urbanization, Age-Dependency-Ratio, Share of Manufacture, Share of Subsistence Farming, Net Migration, Number of Micro-Enterprises, Adjusted Total Fertility Rate, Unemployment Rate), county characteristics (Ethnic Fractionalization), and ethnicity characteristics (Ln of Past Slave Exports per Area).

Table 10: Trust in Known People. 


\begin{tabular}{|c|c|c|c|c|c|c|c|}
\hline & \multicolumn{7}{|c|}{ Dependent variable: Trust in Relatives in 2008} \\
\hline & (1) & $(2)$ & (3) & (4) & (5) & (6) & (7) \\
\hline \multirow[t]{2}{*}{ All fighting } & $-0.99 * * *$ & $-1.00 * * *$ & -0.83 & -0.64 & & & \\
\hline & $(0.34)$ & $(0.22)$ & $(0.70)$ & $(0.75)$ & & & \\
\hline \multirow[t]{2}{*}{ Insecure } & & & & $-0.05 * *$ & & & \\
\hline & & & & $(0.02)$ & & & \\
\hline \multirow[t]{2}{*}{ Violence Civil. } & & & & & -1.70 & & \\
\hline & & & & & (1.59) & & \\
\hline \multirow{2}{*}{ Battles } & & & & & & -1.39 & \\
\hline & & & & & & (1.10) & \\
\hline \multirow[t]{2}{*}{ IDP } & & & & & & & -0.09 \\
\hline & & & & & & & $(0.09)$ \\
\hline Method & Probit & OLS & $2 S L S$ & $2 S L S$ & $2 S L S$ & $2 S L S$ & 2SLS \\
\hline Observations & 2245 & 2257 & 2257 & 2257 & 2257 & 2257 & 2257 \\
\hline Pseudo R-squared & 0.072 & 0.070 & 0.070 & 0.072 & 0.068 & 0.071 & 0.067 \\
\hline \multicolumn{8}{|c|}{$\begin{array}{l}\text { Note: The unit of observation is an individual. Robust standard errors in parenthesis (adjusted in all Probit regressions for } \\
\text { clustering at county level, and in all OLS and } 2 \text { SLS regressions for two-way clustering at county and ethnicity level). } \\
\text { Significance levels } * p<0.1, * * p<0.05, * * * p<0.01 \text {. All specifications control for unreported individual sociodemographics } \\
\text { (Age, Education, Employed, Gender, Rural, Own TV, Own Radio, } 17 \text { Religion Fixed Effects), districts characteristics at the } \\
\text { beginning of the period (Past Generalized Trust, Past Trust in Own Group, Past Ethnic Identity, Population, Urbanization, } \\
\text { Age-Dependency-Ratio, Share of Manufacture, Share of Subsistence Farming, Net Migration, Number of Micro-Enterprises, } \\
\text { Adjusted Total Fertility Rate, Unemployment Rate), county characteristics (Ethnic Fractionalization), and ethnicity } \\
\text { characteristics (Ln of Past Slave Exports per Area). }\end{array}$} \\
\hline
\end{tabular}

Table 11: Trust in Relatives. 
Panel A

\begin{tabular}{l|ccccc}
\hline \hline Dep. var: & All fight. & All fight. & Viol. Civ. & Battles & IDP \\
\hline & $(1)$ & $(2)$ & $(3)$ & $(4)$ & $(5)$ \\
\hline Dist. from Sudan & $-0.12^{* * *}$ & $-0.12^{* * *}$ & $-0.06^{* * *}$ & $-0.07^{* * *}$ & $-0.96^{* * *}$ \\
& $(0.02)$ & $(0.02)$ & $(0.01)$ & $(0.02)$ & $(0.13)$ \\
Max. elevation & $0.01^{* * *}$ & $0.01^{* * *}$ & $0.00^{* *}$ & $0.01^{* * *}$ & $0.05^{* * *}$ \\
& $(0.00)$ & $(0.01)$ & $(0.00)$ & $(0.00)$ & $(0.01)$ \\
\hline Method & OLS & OLS & OLS & OLS & OLS \\
Observations & 2259 & 2259 & 2259 & 2259 & 2259 \\
R-squared & 0.775 & 0.775 & 0.747 & 0.722 & 0.908 \\
Hansen J stat: (p-value) & 0.81 & 0.75 & 0.66 & 0.50 & 0.46 \\
F stat. (Kleibergen-Paap) & 16.81 & 15.89 & 29.55 & 11.89 & 32.53 \\
\hline \hline
\end{tabular}

Note: Standard errors in parenthesis (robust, clustered at the county level). Significance levels * $\mathrm{p}<0.1, * * \mathrm{p}<0.05, * * * \mathrm{p}<0.01$.

Panel B

\begin{tabular}{|c|c|c|c|c|c|c|}
\hline \multirow[t]{2}{*}{ Dep.var: } & \multicolumn{6}{|c|}{ Ethnic Identity in 2008 (Second stage) } \\
\hline & $(1)$ & $(2)$ & (3) & (4) & $(5)$ & (6) \\
\hline All fighting & $\begin{array}{c}2.86 * * \\
(1.19)\end{array}$ & $\begin{array}{c}3.48 * * * \\
(1.27)\end{array}$ & $\begin{array}{c}2.86 * * \\
(1.19)\end{array}$ & & $\begin{array}{c}3.38 * * * \\
(1.20)\end{array}$ & $\begin{array}{c}2.69 * * \\
(1.20)\end{array}$ \\
\hline Dist. from Sudan & & & & $\begin{array}{c}-0.38 * * * \\
(0.08)\end{array}$ & & \\
\hline Max. elevation & & & & $\begin{array}{c}0.04 \\
(0.03)\end{array}$ & & \\
\hline Method & $2 S L S$ & $2 S L S$ & 2SLS (LIML) & OLS & $2 S L S$ & $2 S L S$ \\
\hline Instruments & Sudan, elev. & Sudan & Sudan, elev. & $\mathrm{n} / \mathrm{a}$ & Sudan, elev. & Sudan \\
\hline Observations & 2259 & 2259 & 2259 & 2259 & 117 & 117 \\
\hline R-squared & 0.04 & 0.036 & 0.04 & 0.065 & 0.408 & 0.48 \\
\hline Hansen J stat ( $p$-value) & 0.81 & $\mathrm{n} / \mathrm{a}$ & 0.81 & $\mathrm{n} / \mathrm{a}$ & 0.38 & $\mathrm{n} / \mathrm{a}$ \\
\hline F stat. (Kleibergen-Paap) & 16.81 & 21.26 & 16.81 & $\mathrm{n} / \mathrm{a}$ & $\mathrm{n} / \mathrm{a}$ & $\mathrm{n} / \mathrm{a}$ \\
\hline F stat. (Cragg-Donald) & $\mathrm{n} / \mathrm{a}$ & $\mathrm{n} / \mathrm{a}$ & $\mathrm{n} / \mathrm{a}$ & $\mathrm{n} / \mathrm{a}$ & 8.87 & 12.01 \\
\hline
\end{tabular}

Table 12: First Stage of Benchmark Regressions (Panel A) and Robustness IV (Panel B) for Identity. 


\begin{tabular}{lcccc}
\hline \hline Dep. var.: & Gen. Trust & Gen. Trust & Identity & Identity \\
\hline Model: & $(3)$ & $(4)$ & $(7)$ & $(8)$ \\
\hline All fighting & $-5.64^{* * *}$ & $-6.22^{* * *}$ & $4.70^{* * *}$ & $4.64^{* * *}$ \\
& $(1.94)$ & $(1.85)$ & $(1.73)$ & $(1.41)$ \\
\hline Method & 2 SLS & 2 SLS & 2 SLS & 2 SLS \\
Sample & w/o AchGREG & w/o AchETHN & w/o AchGREG & w/o AchETHN \\
Observations & 1966 & 2156 & 1973 & 2163 \\
R-squared & 0.137 & 0.121 & 0.050 & 0.042 \\
\hline \hline
\end{tabular}

Note: The unit of observation is an individual. Robust standard errors in parenthesis (adjusted in all Probit regressions for clustering at county level, and in all OLS and 2SLS regressions for twoway clustering at county and ethnicity level). Significance levels $* p<0.1, * * p<0.05,{ }^{* * *} p<0.01$. All specifications control for unreported individual sociodemographics (Age, Education, Employed, Gender, Rural, Own TV, Own Radio, 17 Religion Fixed Effects), districts characteristics at the beginning of the period (Past Generalized Trust, Past Trust in Own Group, Past Ethnic Identity, Population, Urbanization, Age-Dependency-Ratio, Share of Manufacture, Share of Subsistence Farming, Net Migration, Number of Micro-Enterprises, Adjusted Total Fertility Rate, Unemployment Rate), county characteristics (Ethnic Fractionalization), and ethnicity characteristics (Ln of Past Slave Exports per Area).

Table 13: Robustness to removing Acholi regions 


\begin{tabular}{lcccc}
\hline \hline Dep. Var: & \multicolumn{3}{c}{ Generalized trust in 2008 (ordinal scale) } \\
\hline Model: & $(1)$ & $(2)$ & $(3)$ & $(4)$ \\
\hline All fighting & $-4.17^{* * *}$ & & & \\
& $(1.07)$ & & & \\
Viol. Civil. & & $-8.45^{* * *}$ & & \\
& & $(3.05)$ & & \\
Battles & & $-7.20^{* * *}$ & \\
& & & $(1.74)$ & $-1.44^{* * *}$ \\
IDP & & & $(0.24)$ \\
& & & & Ordered \\
& & & Ordered & Probit \\
Method & Ordered & Ordered & Probit & 2252 \\
Observations & 2252 & Probit & 2252 & 0.065 \\
Pseudo R-sq. & 0.060 & 0.058 & 0.061 & \\
\hline \hline
\end{tabular}

Note: The unit of observation is an individual. Standard errors in parenthesis (robust, clustered at county level). Significance levels $* p<0.1, * * p<0.05, * * * p<0.01$. All specifications control for unreported individual sociodemographics (Age, Education, Employed, Gender, Rural, Own TV, Own Radio, 17 Religion Fixed Effects), districts characteristics at the beginning of the period (Past Generalized Trust, Past Trust in Own Group, Past Ethnic Identity, Population, Urbanization, Age-Dependency-Ratio, Share of Manufacture, Share of Subsistence Farming, Net Migration, Number of Micro-Enterprises, Adjusted Total Fertility Rate, Unemployment Rate), county characteristics (Ethnic Fractionalization), and ethnicity characteristics (Ln of Past Slave Exports per Area).

Table 14: Robustness to using Ordered Probit. 


\begin{tabular}{|c|c|c|c|c|c|c|c|}
\hline & \multicolumn{7}{|c|}{ Dependent variable: Ethnic Identity in 2008} \\
\hline & (1) & (2) & (3) & (4) & $(5)$ & (6) & (7) \\
\hline \multirow[t]{2}{*}{ All fighting } & $0.51 * * *$ & $0.52 * * *$ & $0.88 * * *$ & $0.81 * * *$ & & & \\
\hline & $(0.17)$ & $(0.15)$ & $(0.31)$ & $(0.31)$ & & & \\
\hline \multirow[t]{2}{*}{ Insecure } & & & & $0.06 * *$ & & & \\
\hline & & & & $(0.03)$ & & & \\
\hline \multirow[t]{2}{*}{ Violence Civil. } & & & & & $1.72^{* * *}$ & & \\
\hline & & & & & $(0.50)$ & & \\
\hline \multirow[t]{2}{*}{ Battles } & & & & & & $1.63 * *$ & \\
\hline & & & & & & $(0.66)$ & \\
\hline \multirow[t]{2}{*}{ IDP } & & & & & & & $0.43^{* * *}$ \\
\hline & & & & & & & $(0.15)$ \\
\hline Method & Probit & OLS & $2 S L S$ & $2 S L S$ & $2 S L S$ & $2 S L S$ & $2 S L S$ \\
\hline Observations & 2256 & 2259 & 2259 & 2259 & 2259 & 2259 & 2259 \\
\hline Pseudo R-squared & 0.060 & 0.062 & 0.060 & 0.064 & 0.060 & 0.057 & 0.061 \\
\hline 1st stage: Hansen J stat ( $p$-value) & $\mathrm{n} / \mathrm{a}$ & $\mathrm{n} / \mathrm{a}$ & 0.56 & 0.66 & 0.35 & 0.83 & 0.70 \\
\hline 1st stage: F stat (Kleibergen-Paap) & $\mathrm{n} / \mathrm{a}$ & $\mathrm{n} / \mathrm{a}$ & 26.4 & 25.6 & 19.3 & 28 & 26.2 \\
\hline \multicolumn{8}{|c|}{$\begin{array}{l}\text { Note: The unit of observation is an individual. Robust standard errors in parenthesis (adjusted in all Probit regressions for clustering at } \\
\text { district level, and in all OLS and } 2 \text { SLS regressions for two-way clustering at district and ethnicity level). Significance levels } * p<0.1, * * p<0.05 \text {, } \\
* * * p<0.01 \text {. All specifications control for unreported individual sociodemographics (Age, Education, Employed, Gender, Rural, Own TV, Own } \\
\text { Radio, } 17 \text { Religion Fixed Effects), districts characteristics at the beginning of the period (Past Generalized Trust, Past Trust in Own Group, } \\
\text { Past Ethnic Identity, Population, Urbanization, Age-Dependency-Ratio, Share of Manufacture, Share of Subsistence Farming, Net Migration, } \\
\text { Number of Micro-Enterprises, Adjusted Total Fertility Rate, Unemployment Rate), county characteristics (Ethnic Fractionalization), and } \\
\text { ethnicity characteristics (Ln of Past Slave Exports per Area). }\end{array}$} \\
\hline
\end{tabular}

Table 15: Ethnic Identity (District Level). 
Panel A

\begin{tabular}{|c|c|c|c|c|c|}
\hline & \multicolumn{5}{|c|}{ Dependent variable: Generalized Trust in 2008} \\
\hline & $(1)$ & $(2)$ & $(3)$ & (4) & $(5)$ \\
\hline \multirow[t]{2}{*}{ All fighting } & $-1.34 * * *$ & $-1.39 * * *$ & & & \\
\hline & $(0.30)$ & $(0.47)$ & & & \\
\hline \multirow[t]{2}{*}{ Violence Civil. } & & & $-2.67 * *$ & & \\
\hline & & & $(1.10)$ & & \\
\hline \multirow[t]{2}{*}{ Battles } & & & & $-2.66 * * *$ & \\
\hline & & & & $(0.80)$ & \\
\hline \multirow[t]{2}{*}{ IDP } & & & & & $-0.65 * * *$ \\
\hline & & & & & $(0.20)$ \\
\hline Method & OLS & $2 S L S$ & $2 S L S$ & $2 S L S$ & 2SLS \\
\hline Observations & 49 & 49 & 49 & 49 & 49 \\
\hline Pseudo R-squared & 0.664 & 0.664 & 0.632 & 0.670 & 0.683 \\
\hline
\end{tabular}

Note: The unit of observation is a district. Robust standard errors in parenthesis. Significance levels * $p<0.1, * * p<0.05, * * * p<0.01$. All specifications control for unreported districts characteristics at the beginning of the period (Past Generalized Trust, Past Trust in Own Group, Past Ethnic Identity, Population, Urbanization, Age-Dependency-Ratio, Share of Manufacture, Share of Subsistence Farming, Net Migration, Number of Micro-Enterprises, Adjusted Total Fertility Rate, Unemployment Rate, Ethnic Fractionalization, Ln of Past Slave Exports per Area).

\section{Panel B}

\begin{tabular}{|c|c|c|c|c|c|}
\hline & \multicolumn{5}{|c|}{ Dependent variable: Ethnic Identity in 2008} \\
\hline & (1) & (2) & (3) & (4) & (5) \\
\hline \multirow[t]{2}{*}{ All fighting } & $0.46^{*}$ & $0.90 * *$ & & & \\
\hline & $(0.26)$ & $(0.41)$ & & & \\
\hline \multirow[t]{2}{*}{ Violence Civil. } & & & $1.68^{* *}$ & & \\
\hline & & & $(0.83)$ & & \\
\hline \multirow[t]{2}{*}{ Battles } & & & & $1.77^{* *}$ & \\
\hline & & & & $(0.80)$ & \\
\hline \multirow[t]{2}{*}{ IDP } & & & & & $0.43^{* *}$ \\
\hline & & & & & $(0.19)$ \\
\hline Method & OLS & $2 S L S$ & $2 S L S$ & $2 S L S$ & $2 S L S$ \\
\hline Observations & 49 & 49 & 49 & 49 & 49 \\
\hline Pseudo R-squared & 0.352 & 0.313 & 0.318 & 0.291 & 0.319 \\
\hline
\end{tabular}

Note: The unit of observation is a district. Robust standard errors in parenthesis. Significance levels * $p<0.1, * * p<0.05, * * * p<0.01$. All specifications control for unreported districts characteristics at the beginning of the period (Past Generalized Trust, Past Trust in Own Group, Past Ethnic Identity, Population, Urbanization, Age-Dependency-Ratio, Share of Manufacture, Share of Subsistence Farming, Net Migration, Number of Micro-Enterprises, Adjusted Total Fertility Rate, Unemployment Rate, Ethnic Fractionalization, Ln of Past Slave Exports per Area).

Table 16: Main regressions with data collapsed at the district level. 


\begin{tabular}{lcccc}
\hline \hline Dep. Var: & Trust gen. & Trust know. & Trust rel. & Identity \\
\hline Model: & $(1)$ & $(2)$ & $(3)$ & $(4)$ \\
\hline All fighting & $-4.15^{* * *}$ & $-3.41^{* * *}$ & -0.80 & $2.89 * * *$ \\
& $(1.21)$ & $(1.01)$ & $(0.81)$ & $(1.04)$ \\
\hline Method & IVProbit & IVProbit & IVProbit & IVProbit \\
Observations & 2242 & 2240 & 2245 & 2256 \\
Log Pseudolikelihood & 4067.44 & 3877.14 & 4389.80 & 4278.17 \\
\hline \hline
\end{tabular}

Note: The unit of observation is an individual. Standard errors in parenthesis (robust, clustered at county level). Significance levels $* p<0.1,{ }^{* *} p<0.05, * * * p<0.01$. All specifications control for unreported individual sociodemographics (Age, Education, Employed, Gender, Rural, Own TV, Own Radio, 17 Religion Fixed Effects), districts characteristics at the beginning of the period (Past Generalized Trust, Past Trust in Own Group, Past Ethnic Identity, Population, Urbanization, Age-Dependency-Ratio, Share of Manufacture, Share of Subsistence Farming, Net Migration, Number of Micro-Enterprises, Adjusted Total Fertility Rate, Unemployment Rate), county characteristics (Ethnic Fractionalization), and ethnicity characteristics (Ln of Past Slave Exports per Area).

Table 17: Robustness to using IVProbit. 


\section{Appendix B (not for publication): Data}

\section{Variables used in Section 3.3}

First the dependent variables:

Generalized trust (in 2008): This is a dummy variable varying on the individual level and taking a value of 1 if "I trust them somewhat" or "I trust them a lot" is answered to the question "How much do you trust each of the following types of people: Other Ugandans?" from the Afrobarometer 2008 (question Q84C).

Trust in Known People (in 2008): This is a dummy variable varying on the individual level and taking a value of 1 if "I trust them somewhat" or "I trust them a lot" is answered to the question "How much do you trust each of the following types of people: Other people you know?" from the Afrobarometer 2008 (question Q84B).

Trust in relatives (in 2008): This is a dummy variable varying on the individual level and taking a value of 1 if "I trust them somewhat" or "I trust them a lot" is answered to the question "How much do you trust each of the following types of people: Your relatives?" from the Afrobarometer 2008 (question Q84A).

Ethnic identity (in 2008): This is a dummy variable varying on the individual level and taking a value of 1 if "I feel only ( $R$ 's ethnic group)" or "I feel more ( $R$ 's ethnic group) than Ugandan" is answered to the question "Let us suppose that you had to choose between being a Ugandan and being a _ [R's Ethnic Group]. Which of the following best expresses your feelings?" from the Afrobarometer 2008 (question Q83).

The main independent variables:

Generalized trust (in 2000): This is a continuous district level variable that gives the percentage of respondents in a given district who answer "Most people can be trusted" to the question "Generally speaking, would you say that most people can be trusted or that you must be very careful in dealing with people?" from the Afrobarometer 2000 (question Q59).

Trust in other groups (in 2000): This is a continuous district level variable that gives the percentage of respondents in a given district who answer "I trust them somewhat" or "I trust them a lot" to the question "I am now going to read you a list of people and organizations. How much do you trust each of them to do what is right? Ugandans from other ethnic groups" from the Afrobarometer 2000 (question Q60B).

Trust in own group (in 2000): This is a continuous district level variable that gives the percentage of respondents in a given district who answer "I trust them somewhat" or "I trust them a lot" to the question "I am now going to read you a list of people and organizations. How much do you trust each of them to do what is right? Someone from your own ethnic group" from the Afrobarometer 2000 (question Q60A).

Ethnic identity (in 2000): This is a continuous district level variable that gives the percentage of respondents in a given district who answer "Ethnic" to the question "We have spoken to many 


\begin{tabular}{|c|c|c|c|c|c|}
\hline Variable & Obs & Mean & Std. Dev. & Min & Max \\
\hline \multicolumn{6}{|c|}{ Trust variables: } \\
\hline Trust generalized 2008 & 2424 & .3180693 & .4658226 & 0 & 1 \\
\hline Trust known people 2008 & 2422 & .5396367 & .4985294 & 0 & 1 \\
\hline Trust relatives 2008 & 2429 & .8369699 & .3694692 & 0 & 1 \\
\hline Ethnic identity 2008 & 2431 & .2073221 & .4054717 & 0 & 1 \\
\hline Trust generalized 2000 & 2279 & .1553152 & .1020895 & 0 & .34375 \\
\hline Trust own group 2000 & 2279 & .8197781 & .1325227 & .4722222 & 1 \\
\hline Trust in others 2000 & 2279 & .7015967 & .1357914 & .3958333 & .9375 \\
\hline Ethnic identity 2000 & 2279 & 0.1212459 & 0.0804707 & 0 & 0.3191489 \\
\hline Ln slave exports per area & 2431 & 0.0323932 & 0.0678196 & 0 & 0.8487026 \\
\hline \multicolumn{6}{|c|}{ Fighting variables (main specification): } \\
\hline Fighting events & 2431 & 21.3262 & 45.9608 & 0 & 227 \\
\hline Violence against civilians & 2431 & 7.946935 & 16.83046 & 0 & 94 \\
\hline Battles & 2431 & 9.881119 & 26.42823 & 0 & 141 \\
\hline IDP & 2431 & 0.0993206 & 0.250148 & 0 & 0.9458593 \\
\hline \multicolumn{6}{|c|}{ Socio-demographic variables: } \\
\hline Age & 2421 & 33.70921 & 12.28614 & 18 & 81 \\
\hline Education & 2431 & .4960921 & .5000876 & 0 & 1 \\
\hline Own TV & 2428 & .1214992 & .3267738 & 0 & 1 \\
\hline Own radio & 2430 & .7353909 & .4412156 & 0 & 1 \\
\hline Employed & 2431 & .3973673 & .4894539 & 0 & 1 \\
\hline Female & 2431 & 1.499383 & .5001025 & 1 & 2 \\
\hline Urban & 2431 & 1.79926 & .4006367 & 1 & 2 \\
\hline \multicolumn{6}{|c|}{ District level variables: } \\
\hline Population & 2431 & 588125.4 & 277121.5 & 127064 & 1189142 \\
\hline Urbanization & 2431 & 13.28453 & 22.4144 & 1.1 & 100 \\
\hline Age Dependency Ratio & 2431 & 110.7223 & 14.7269 & 64.2 & 132.8 \\
\hline Fractionalization & 2431 & .131371 & .1885135 & 0 & .6659015 \\
\hline Manufacturing Share & 2431 & 2.39239 & 1.952001 & .2 & 9.5 \\
\hline Subsistence Farming & 2431 & 30.64801 & 21.05091 & 7.5 & 97.9 \\
\hline Net Migration & 2431 & 0.1250925 & 5.878295 & -11.4 & 17.5 \\
\hline Number of Micro Enterprises & 2431 & 28193.41 & 22450.44 & 3952 & 103913 \\
\hline Adjusted Fertility Rate & 2431 & 6.964583 & 0.967756 & 4 & 8.2 \\
\hline Unemployment & 2431 & 4.572151 & 3.145646 & 0.8 & 15.4 \\
\hline \multicolumn{6}{|c|}{ Living condition variables: } \\
\hline Living conditions 2008 & 2420 & .4801653 & .4997097 & 0 & 1 \\
\hline Living conditions 2000 & 2279 & .5599112 & .1426186 & .2363636 & .8125 \\
\hline \multicolumn{6}{|c|}{ Instruments: } \\
\hline Distance from Sudan (in km) & 2431 & 271.0786 & 132.5202 & 0 & 529.7582 \\
\hline Maximum elevation & 2431 & 1605.039 & 748.8192 & 875 & 4688 \\
\hline \multicolumn{6}{|c|}{ Satellite Light: } \\
\hline Satellite Light 2008 & 125 & .2728527 & .8278942 & 0 & 6.753723 \\
\hline Satellite Light 2000 & 125 & .3233163 & .8965602 & 0 & 7.117774 \\
\hline
\end{tabular}

Table 18: Descriptive Statistics 
Ugandans and they have all described themselves in different ways. Some people describe themselves in terms of their region, language, ethnic group, religion, or gender. Others describe themselves in economic terms, such as working class, middle class, or according to their occupation (e.g. a farmer or a housewife). Besides being Ugandan, which specific group do you feel you belong to first and foremost?" from the Afrobarometer 2000 (question Q18).

Slave Exports by Area: This is the main slave trade variable from Nunn and Wantchekon (2011), i.e. $\ln (1+[$ number of slave exports]/area).

Insecure: This is a dummy variable varying on the individual level and taking a value of 0 if "Never" is answered and a value of 1 if "Just once or twice", "Several times", "Many times", "Always", or "Don't know" is answered to the question "Over the past year, how often, if ever, have you or anyone in your family: Been physically attacked?" from the Afrobarometer 2008 (question Q9C).

Fighting (County): Taking the Acled (2011) dataset, we have generated with the help of ArcGIS the number of violent events per county. In particular, this variable varies on the county level, and corresponds to the total amount of all violent events in a county taking place between the last day of the Afrobarometer 2000 survey (on June 26, 2000) and the first day of the Afrobarometer 2008 survey (on July 27, 2008). It corresponds to the sum of the events of the following "Event Type": "Battle-Government regains territory", "Battle-No change of territory", "Battle-Rebels gain territory", "Riots/Protests", and "Violence against civilians".

Violence Against Civilians (County): Taking the Acled (2011) dataset, we have generated with the help of ArcGIS the number of violent events per county. In particular, this variable varies on the county level, and corresponds to the total amount of all events of the "Event Type" of "Violence against civilians" in a county taking place between the last day of the Afrobarometer 2000 survey (on June 26, 2000) and the first day of the Afrobarometer 2008 survey (on July 27, 2008).

Battles (County): Taking the Acled (2011) dataset, we have generated with the help of ArcGIS the number of violent events per county. In particular, this variable varies on the county level, and corresponds to the total amount of all battle events in a county taking place between the last day of the Afrobarometer 2000 survey (on June 26, 2000) and the first day of the Afrobarometer 2008 survey (on July 27, 2008). Concretely, it corresponds to the sum of the events of the following "Event Type": "Battle-Government regains territory", "Battle-No change of territory", and "Battle-Rebels gain territory".

Internally Displaced People (IDP): Total number of internally displaced people per district in 2006 (From UNHCR, 2006).

Fighting (Tribe): Taking the Acled (2011) dataset, we have matched all fighting events to a particular tribe (Q79) in the Afrobarometer 2008 survey (where feasible). In particular, this variable varies on the tribe level, and corresponds to the total amount of all violent events linked to a tribe taking place between the last day of the Afrobarometer 2000 survey (on June 26, 2000) and the first day of the Afrobarometer 2008 survey (on July 27, 2008). It corresponds to the sum of the events of 
the following "Event Type": "Battle-Government regains territory", "Battle-No change of territory", "Battle-Rebels gain territory", "Riots/Protests", and "Violence against civilians".

Fighting (Tribe, County): Taking the Acled (2011) dataset, we have generated with the help of ArcGIS the number of violent events per county and tribe (Q79). In particular, this variable varies on the county and tribe level, and corresponds to the total amount of all violent events in a county and linked to a given tribe taking place between the last day of the Afrobarometer 2000 survey (on June 26, 2000) and the first day of the Afrobarometer 2008 survey (on July 27, 2008). It corresponds to the sum of the events of the following "Event Type": "Battle-Government regains territory", "Battle-No change of territory", "Battle-Rebels gain territory", "Riots/Protests", and "Violence against civilians".

Additional individual level controls (not reported in the main Tables):

Age: Continuous variable that varies on the individual level. Answer to the question "How old are you?" (question Q1) of the Afrobarometer 2008.

Education: Dummy variable that varies on the individual level. Takes a value of 1 if the respondent indicates at least an education level of 4 in the question Q89 of the Afrobarometer 2008.

Employed: Dummy variable that varies on the individual level. From Afrobarometer 2008. It takes a value of 1 if "yes" (answer categories 2,3,4, and 5) is answered to the question "Do you have a job that pays a cash income?" (question Q94).

Gender: Variable that varies on the individual level. 1=Male, 2=Female. From question Q101 of the Afrobarometer 2008.

Rural: Variable that varies on the individual level. 1=Urban, $2=$ Rural. From question URBRUR of the Afrobarometer 2008.

Own Radio: Dummy variable that varies on the individual level. From Afrobarometer 2008. It takes a value of 1 if "Yes (Do own)" is answered to the question "Which of these things do you personally own: Radio?" (question Q92A).

Own TV: Dummy variable that varies on the individual level. From Afrobarometer 2008. It takes a value of 1 if "Yes (Do own)" is answered to the question "Which of these things do you personally own: Television?" (question Q92B).

Additional district/county level controls (not reported in the main Tables):

Adjusted Total Fertility Rate: Adjusted total fertility rate in a given district in 2002. From the Census 2002 (Ugandan Bureau of Statistics, 2002).

Age Dependency Ratio: Age dependency ratio in district in 2002. From the Census 2002 (Ugandan Bureau of Statistics, 2002).

Ethnic Fractionalization: This is a continuous county level variable that varies between 0 and 1. Using the Geo-Referenced Ethnic Group (GREG) dataset (Weidmann, Rød and Cederman, 2010), we obtain with the help of ArcGIS the percentage of the area of a given county that is occupied by a given ethnic group. For each county fractionalization is computed using the following formula: $F R A C=\sum_{i=1}^{n} \operatorname{share~}_{i} *\left(1-\right.$ share $\left._{i}\right)$.

Net migration: Net migration in a given district in 2002. From the Census 2002 (Ugandan 
Bureau of Statistics, 2002).

Number of Micro-Enterprises: Number of micro-enterprises in a given district in 2002. From the Census 2002 (Ugandan Bureau of Statistics, 2002).

Population: Total population in district in 2002. From the Census 2002 (Ugandan Bureau of Statistics, 2002).

Share of Manufacture: Percentage of working population that are in the manufacturing sector in a given district in 2002. From the Census 2002 (Ugandan Bureau of Statistics, 2002).

Share of Subsistence Farming: Percentage of working population that are in subsistence farming in a given district in 2002. From the Census 2002 (Ugandan Bureau of Statistics, 2002).

Unemployment Rate: Unemployment rate in a given district in 2002. From the Census 2002 (Ugandan Bureau of Statistics, 2002).

Urbanization: Urbanization rate in district in 2002. From the Census 2002 (Ugandan Bureau of Statistics, 2002).

Ethnic (Tribe) FE: From variable Q79 ("What is your tribe? You know, your ethnic or cultural group.") of Afrobarometer 2008.

Religion FE: From variable Q90 ("What is your religion, if any?") of Afrobarometer 2008.

\section{Variables used in Section 5}

Now we shall list the additional variables included in the empirical analysis of Section 5 . Note that when a variable is not listed this means that the variable definition detailed above applies. Further, notice that for the living conditions regressions all variables are used on the individual level, while for the satellite light regressions they are aggregated at the county level.

Living conditions (in 2008): This is a dummy variable varying on the individual level and taking a value of 1 if "Neither good nor bad", "Fairly good", or "Very good" is answered to the question "In general, how would you describe: Your own present living conditions?" from the Afrobarometer 2008 (question Q4B).

Living conditions (in 2000): This is a continuous district level variable that gives the percentage of respondents in a given district who answer "Somewhat satisfied" or "Very satisfied" to the question "How satisfied are you with: A. Your own living conditions today?" from the Afrobarometer 2000 (question Q8A).

Satellite nightlight (in 2000 and 2008): The data comes from the National Oceanic and Atmospheric Administration (2010). We use their data on Average Visible, Stable Lights, \& Cloud Free Coverages of their satellite F15/F16. In particular, we use their "cleaned" and "filtered" version of the data, which "contains the lights from cities, towns, and other sites with persistent lighting, including gas flares. Ephemeral events, such as fires have been discarded. Then the background noise was identified and replaced with values of zero. Data values range from 1-63." Using ArcGIS we generate the county level average nightlight intensity. 